\title{
Design of the Blended Wing Body Subsonic Transport
}

\author{
R. H. Liebeck* \\ The Boeing Company, Huntington Beach, California 92647
}

\begin{abstract}
The Boeing Blended-Wing-Body (BWB) airplane concept represents a potential breakthrough in subsonic transport efficiency. Work began on this concept via a study to demonstrate feasibility and begin development of this new class of airplane. In this initial study, 800-passenger BWB and conventional configuration airplanes were sized and compared for a 7000-n mile design range. Both airplanes were based on engine and structural (composite) technology for a 2010 entry into service. Results showed remarkable performance improvements of the BWB over the conventional baseline, including a $15 \%$ reduction in takeoff weight and a $27 \%$ reduction in fuel burn per seat mile. Subsequent in-house studies at Boeing have yielded the development of a family of BWB transports ranging from 200 to 600 passengers with a high level of parts commonality and manufacturing efficiency. Studies have also demonstrated that the BWB is readily adaptable to cruise Mach numbers as high as 0.95 . The performance improvement of the latest Boeing BWBs over conventional subsonic transports based on equivalent technology has increased beyond the predictions of the early NASA-sponsored studies.
\end{abstract}

\section{Introduction}

I $\mathrm{T}$ is appropriate to begin with a reference to the Wright Flyer itself, designed and first flown in 1903. A short 44 years later, the swept-wing Boeing B-47 took flight. A comparison of these two airplanes shows a remarkable engineering accomplishment within a period of slightly more than four decades. Embodied in the B-47 are most of the fundamental design features of a modern subsonic jet transport: swept wing and empennage and podded engines hung on pylons beneath and forward of the wing. The Airbus A330, designed 44 years after the B-47, appears to be essentially equivalent, as shown in Fig. 1.

Thus, in 1988, when NASA Langley Research Center's Dennis Bushnell asked the question: "Is there a renaissance for the longhaul transport?" there was cause for reflection. In response, a brief preliminary design study was conducted at McDonnell Douglas to create and evaluate alternate configurations. A preliminary configuration concept, shown in Fig. 2, was the result. Here, the pressurized passengercompartmentconsisted of adjacent parallel tubes, a lateral extension of the double-bubble concept. Comparison with a conventional configuration airplane sized for the same design mission indicated that the blended configuration was significantly lighter, had a higher lift to drag ratio, and had a substantially lower fuel burn.

This paper is intended to chronicle the technical development of the Blended-Wing-Body (BWB) concept. Development is broken into three somewhat distinct phases: formulation, initial development and feasibility, and, finally, a description of the current Boeing BWB baseline airplane.

\section{Formulation of the BWB Concept}

The performance potential implied by the blended configuration provided the incentive for NASA Langley Research Center to fund a small study at McDonnell Douglas to develop and compare advanced technology subsonic transports for the design mission of 800 passengers and a 7000-n mile range at a Mach number of 0.85. Composite structure and advanced technology turbofans were utilized.

Defining the pressurized passenger cabin for a very large airplane offers two challenges. First, the square-cubelaw shows that the cabin

Received 9 June 2002; revision received 19 December 2002; accepted for publication 10 January 2003. Copyright (C) 2003 by the American Institute of Aeronautics and Astronautics, Inc. All rights reserved. Copies of this paper may be made for personal or internal use, on condition that the copier pay the $\$ 10.00$ per-copy fee to the Copyright Clearance Center, Inc., 222 Rosewood Drive, Danvers, MA 01923; include the code 0021-866904 $\$ 10.00$ in correspondence with the CCC.

*Boeing Senior Technical Fellow, Phantom Works. Fellow AIAA. surface area per passenger available for emergency egress decreases with increasing passenger count. Second, cabin pressure loads are most efficiently taken in hoop tension. Thus, the early study began with an attempt to use circular cylinders for the fuselage pressure vessel, as shown in Fig. 3, along with the corresponding first cut at the airplane geometry. The engines are buried in the wing root, and it was intended that passengers could egress from the sides of both the upper and lower levels. Clearly, the concept was headed back to a conventional tube and wing configuration. Therefore, it was decided to abandon the requirement for taking pressure loads in hoop tension and to assume that an alternate efficient structural concept could be developed. Removal of this constraint became pivotal for the development of the BWB.

Passenger cabin definition became the origin of the design, with the hoop tension structural requirement deleted. Three canonical forms shown in Fig. 4a, each sized to hold 800 passengers, were considered. The sphere has minimum surface area; however, it is not streamlined. Two canonical streamlined options include the conventional cylinder and a disk, both of which have nearly equivalent surface area. Next, each of these fuselages is placed on a wing that has a total surface area of $15,000 \mathrm{ft}^{2}$. Now the effective masking of the wing by the disk fuselage results in a reduction of total aerodynamic wetted area of $7000 \mathrm{ft}^{2}$ compared to the cylindrical fuselage plus wing geometry, as shown in Fig. 4b. Next, adding engines (Fig. 4c) provides a difference in total wetted area of 10,200 $\mathrm{ft}^{2}$. (Weight and balance require that the engines be located aft on the disk configuration.) Finally, adding the required control surfaces to each configuration as shown in Fig. 4d results in a total wetted area difference of $14,300 \mathrm{ft}^{2}$, or a reduction of $33 \%$. Because the cruise lift to drag ratio is related to the wetted area aspect ratio, $b^{2} / S_{\text {wet }}$, the BWB configuration implied a substantial improvement in aerodynamic efficiency.

The disk fuselage configuration sketched in Fig. 4d has been used to describe the germination of the BWB concept. Synergy of the basic disciplines is strong. The fuselage is also a wing, an inlet for the engines, and a pitch control surface. Verticals provide directional stability, control, and act as winglets to increase the effective aspect ratio. Blending and smoothing the disk fuselage into the wing achieved transformation of the sketch into a realistic airplane configuration. In addition, a nose bullet was added to offer cockpit visibility. This also provides additional effective wing chord at the centerline to offset compressibility drag due to the unsweeping of the isobars at the plane of symmetry.

Modern supercritical airfoils with aft camber and divergent trailing edges were assumed for the outer wing, whereas the centerbody was to be based on a reflexed airfoil for pitch trim. A proper spanload implies a relatively low lift coefficient due to the very large centerbody chords. Therefore, airfoil LW 102A was designed for $c_{l}=0.25$ 


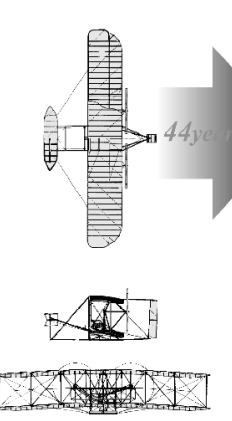

1903
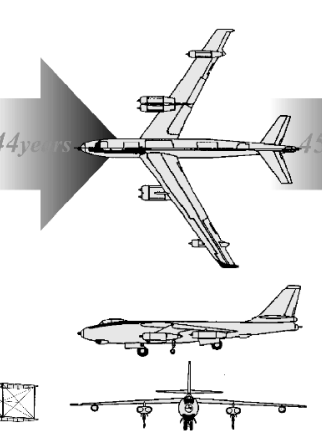

1947

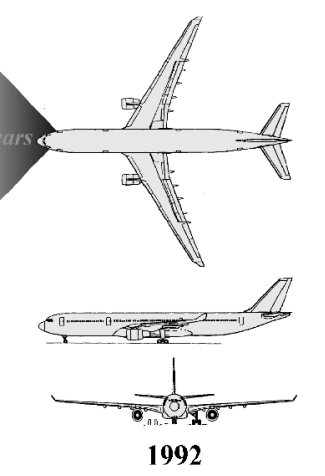

1992
Fig. 1 Aircraft design evolution, the first and second 44 years.

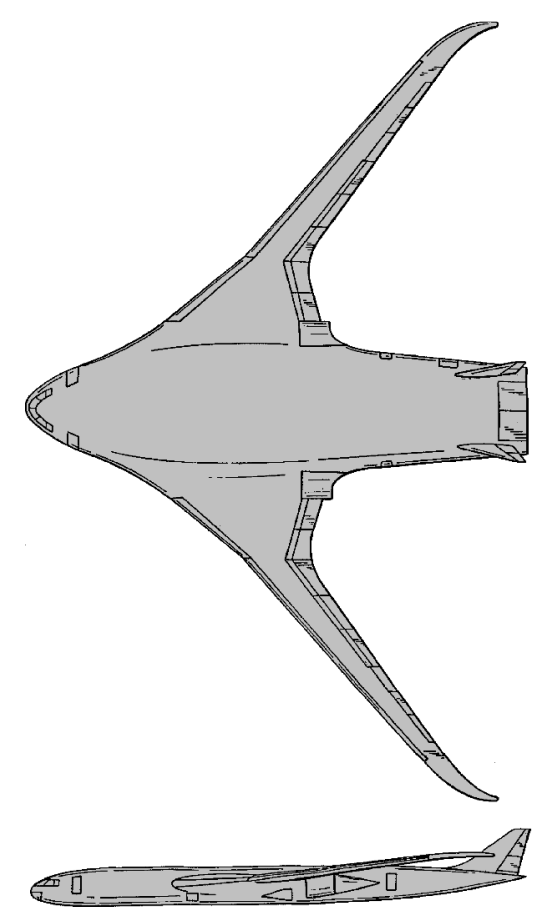

Fig. 2 Early blended configuration concept.

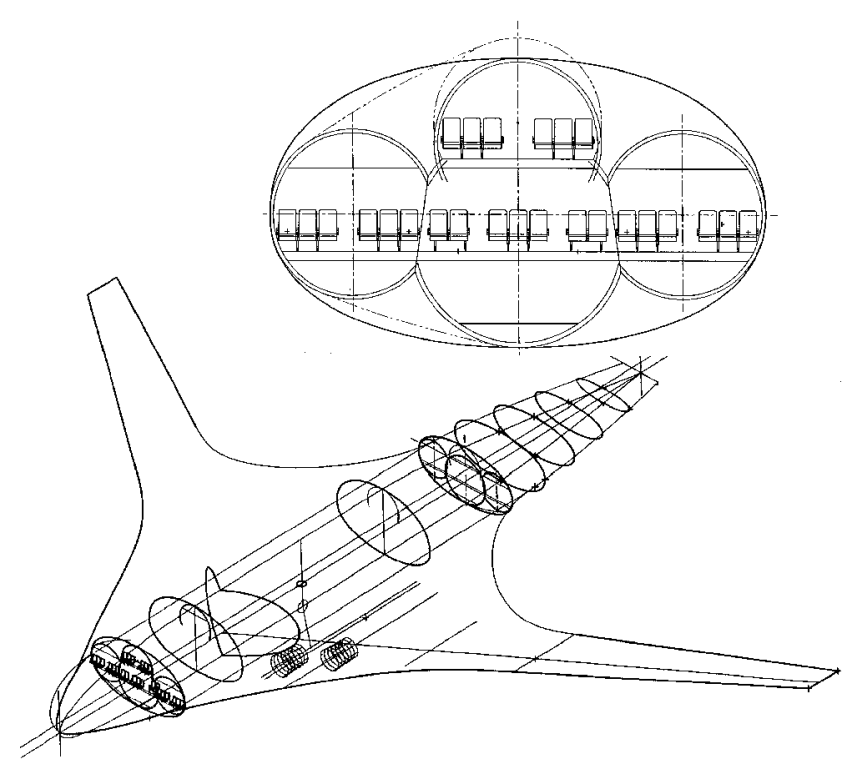

Fig. 3 Early configuration with cylindrical pressure vessel and engines buried in the wing root.

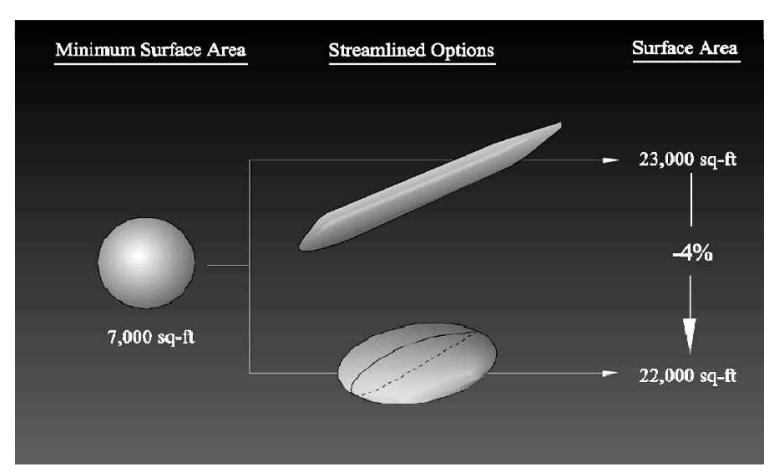

a) Effect of body type on surface area

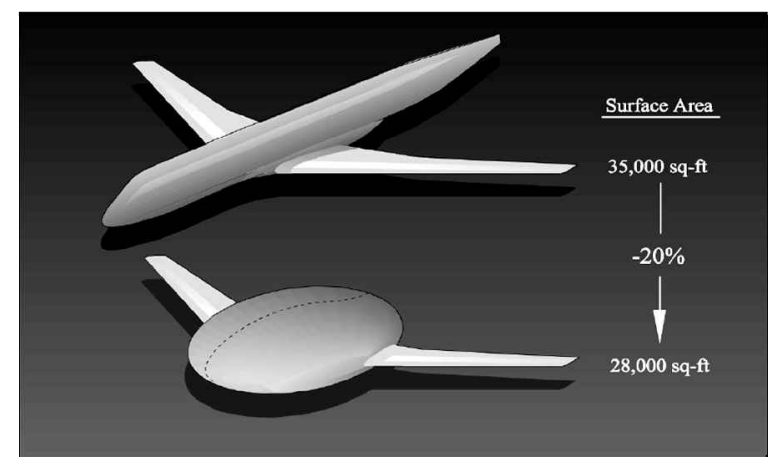

b) Effect of wing/body integration on surface area

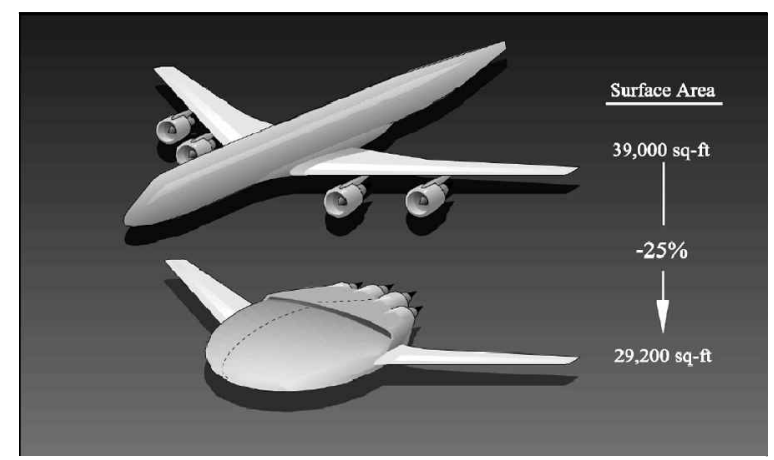

c) Effect of engine installation on surface area

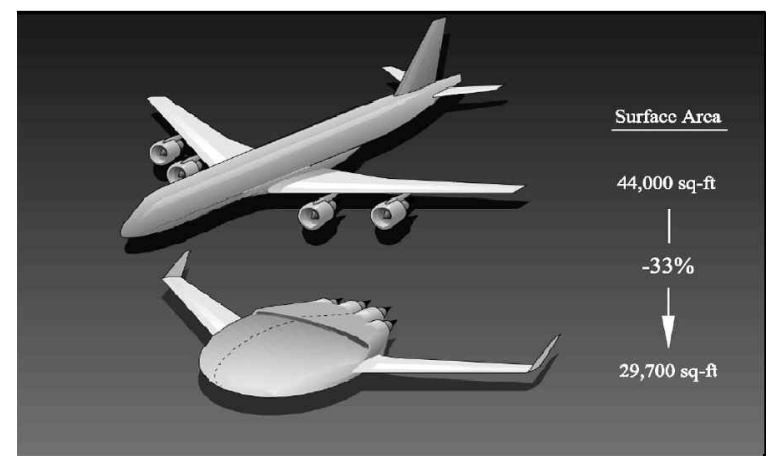

d) Effect of controls integration on surface area

Fig. 4 Genesis of the BWB concept.

and $c_{\mathrm{mc} / 4}=+0.03$ at $M=0.7$ using the method of Ref. 1 . The resulting airfoil section is shown in Fig. 5, along with a planform indicating how pitch trim is accomplished via centerbody reflex, whereas the outboard wing carries a proper spanload all of the way to the wingtip. Blending of this centerbody airfoil with the outboard supercritical sections yielded an aerodynamic configuration with a nearly elliptic spanload. At this early stage of BWB development, the structurally rigid centerbody was regarded as offering free wingspan. Outer wing geometry was essentially taken from a 

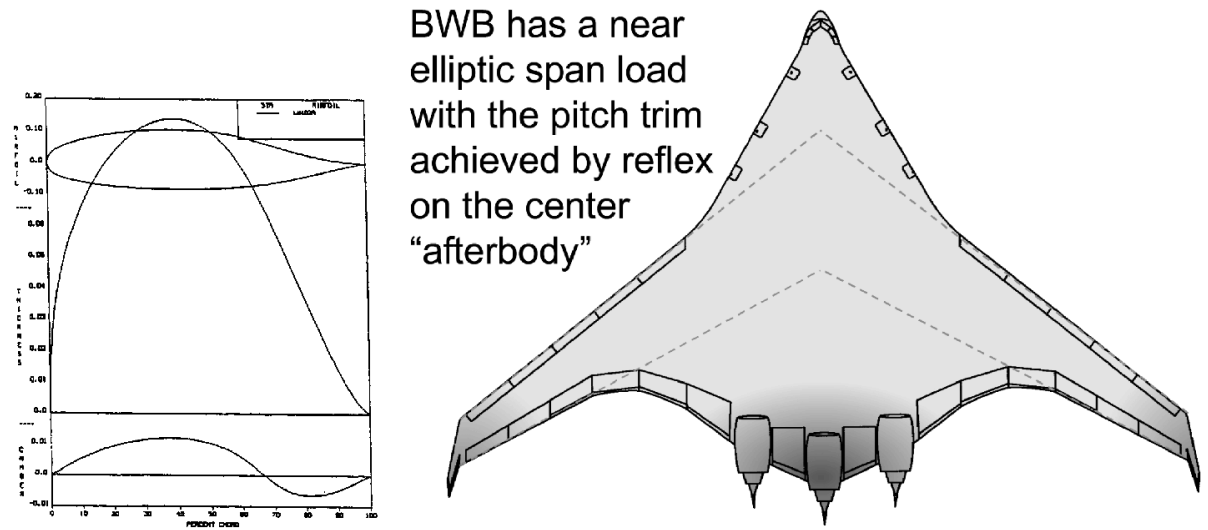

Original Inboard Airfoil Section

Fig. 5 Original centerbody airfoil LW109A and planform showing pitch trim effector.
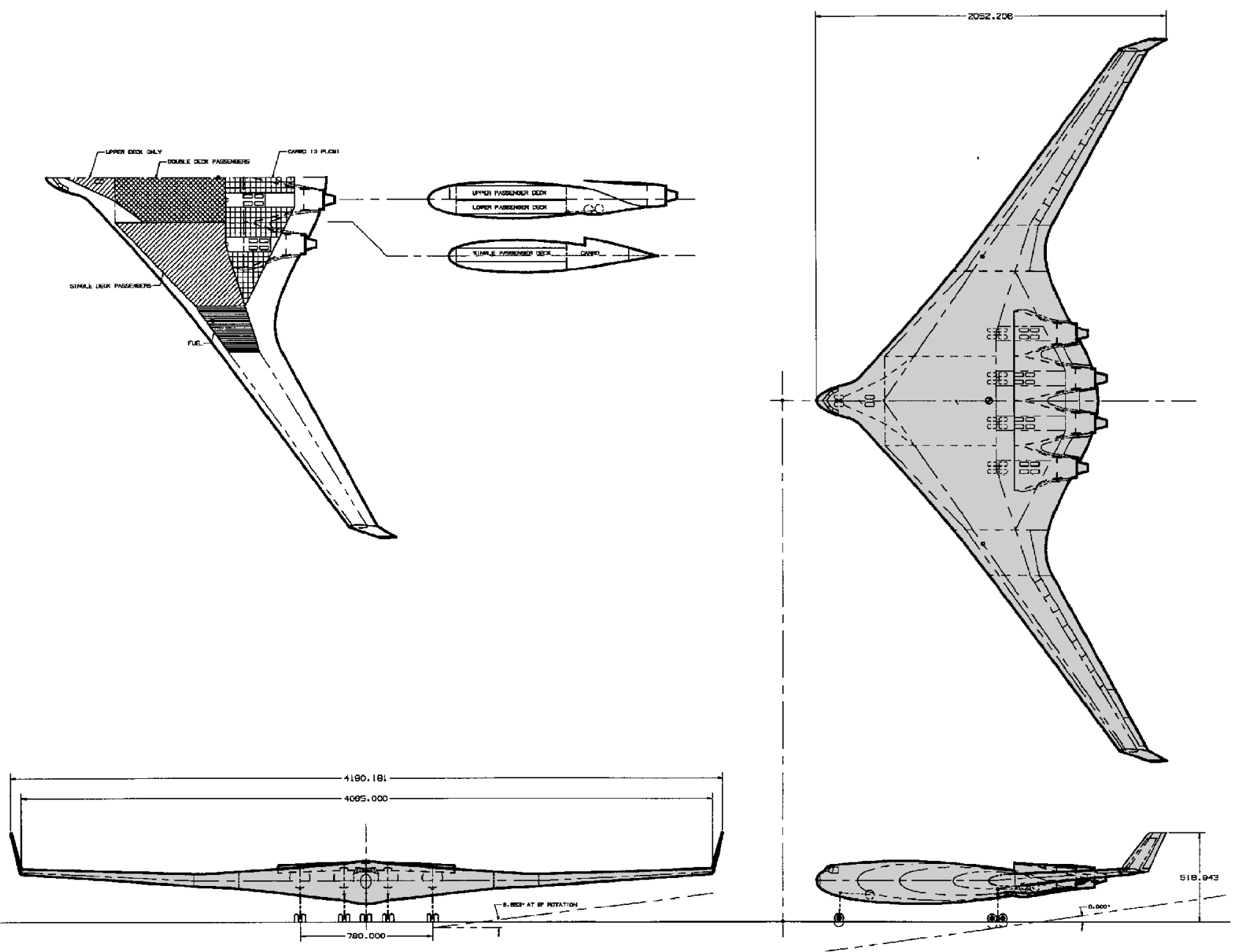

Fig. 6 First-generation BWB.

conventionaltransport and bolted to the side of the centerbody. The result was a wingspan of $349 \mathrm{ft}$, a trapezoidal aspect ratio of 12 , and a longitudinal static margin of $-15 \%$, implying a requirement for a fly-by-wire control system.

The aft engine location, dictated by balance requirements, offered the opportunity for swallowing the boundary layer from that portion of the centerbody upstream of the inlet, a somewhat unique advantage of the BWB configuration. In principle, boundary-layer swallowing can provide improved propulsive efficiency by reducing the ram drag, and this was the motivation for the wide "mail-slot" inlet sketched in Fig. 6. However, this assumed that such an inlet could be designed to provide uniform flow and efficient pressure recovery at the fan face of the engine(s).

Two structural concepts (Fig. 7) were considered for the centerbody pressure vessel. Both required that the cabin be composed of longitudinal compartments to provide for wing ribs $150 \mathrm{in}$. apart to 

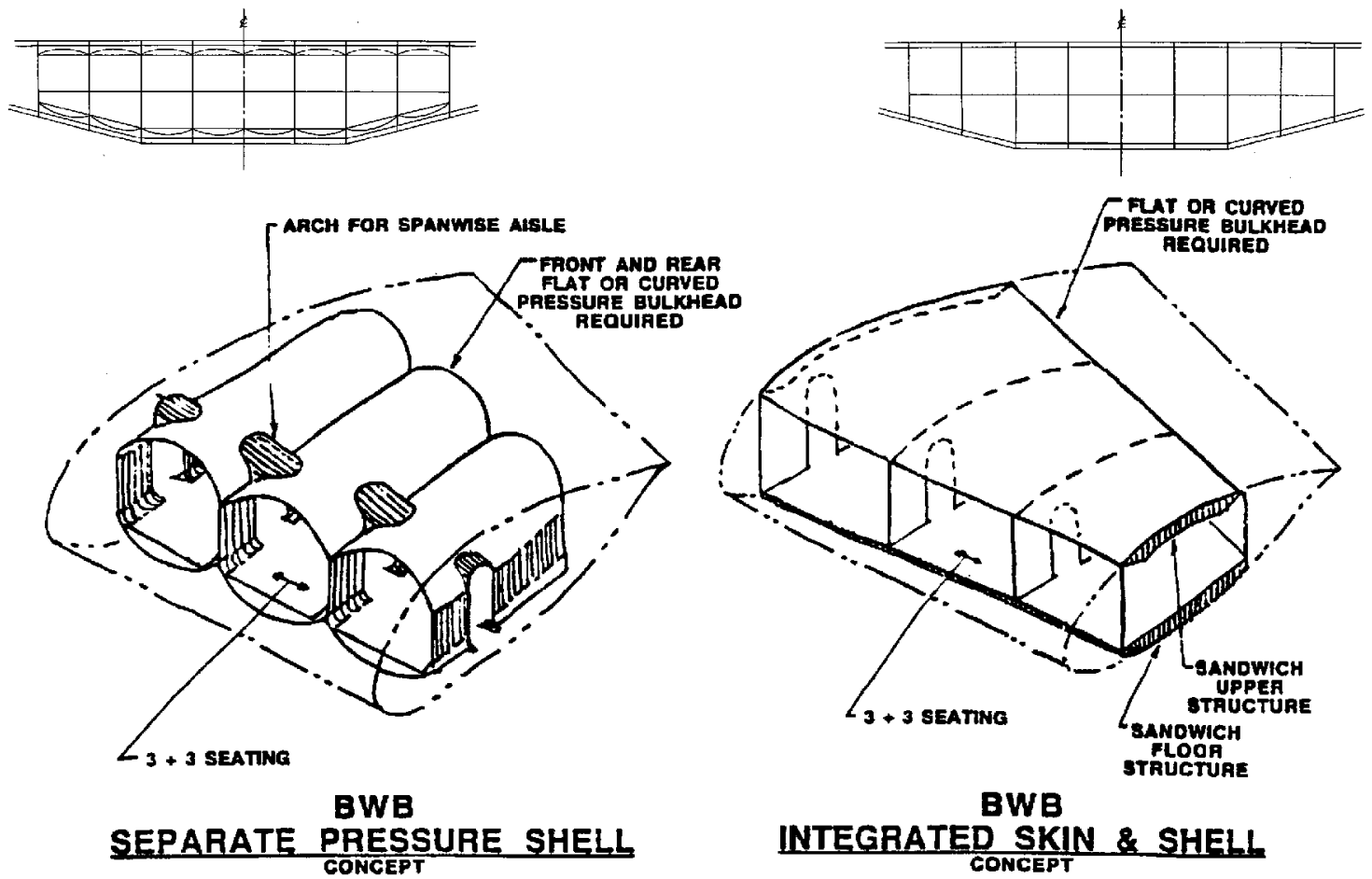

Fig. 7 Centerbody pressure vessel structural concepts.

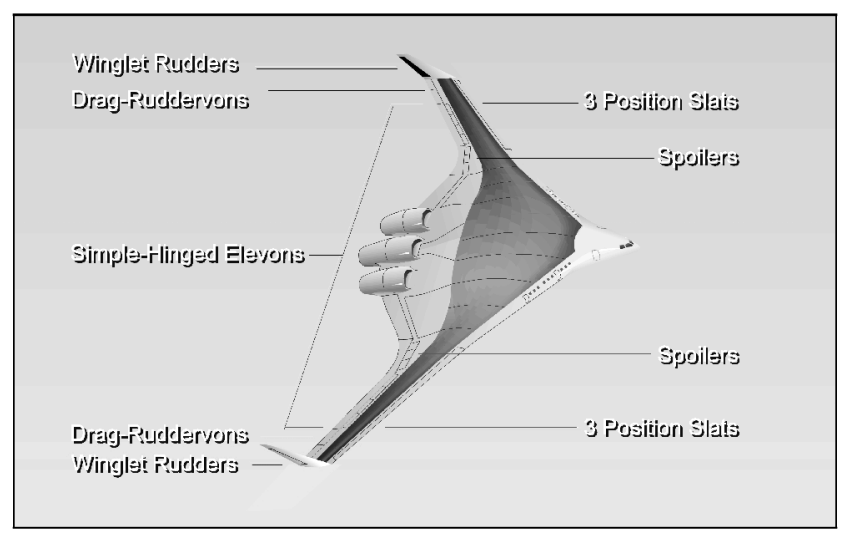

Fig. 8 Flight control system architecture of the first-generation BWB.

carry the pressureload. The first concept used a thin, arched pressure vessel above and below each cabin, where the pressure vessel skin takes the load in tension and is independent of the wing skin. A thick sandwich structure for both the upper and lower wing surfaces was the basis for the second concept. In this case, both cabin pressure loads and wing bending loads are taken by the sandwich structure. A potential safety issue exists with the separate arched pressure vessel concept. If a rupture were to occur in the thin arched skin, the cabin pressure would have to be borne by the wing skin, which must in turn be sized to carry the pressure load. Thus, once the wing skin is sized by this condition, in principle there is no need for the inner pressure vessel. Consequently, the thick sandwich concept was chosen for the centerbody structure. A three-view of the original BWB is given in Fig. 6, and a description of the packaging of the interior is also shown there. Passengers are carried in both single and double deck cabins, and the cargo is carried aft of the passenger cabin. As a tailless configuration, the BWB is a challenge for flight mechanics, and the early control system architecture is shown in the isometric view in Fig. 8. A complete description of original BWB study is given in Ref. 2. Future generations of BWB designs would begin to address constraints not observed by this initial concept, but the basic character of the aircraft persists to this day.

\section{BWB Design Constraints}

As an integrated airplane configuration, the BWB must satisfy a unique set of design requirements. Included are the following:

\section{A. Volume}

Passengers, cargo, and systems must be packaged within the wing itself. This leads to a requirement for the maximum thickness-tochord ratio on the order of $17 \%$, a value that is much higher than is typically associated with transonic airfoils.

\section{B. Cruise Deck Angle}

Because the passenger cabin is packaged within the centerbody, the centerbody airfoils must be designed to generate the necessary lift at an angle of attack consistent with cabin deck angle requirements (typically less than $3 \mathrm{deg}$ ). Taken by itself, this requirement suggests the use of positive aft camber on the centerbody airfoils.

\section{Trim}

A BWB configuration is considered trimmed (at the nominal cruise condition) when the aerodynamic center of pressure is coincident with the center of gravity, and all of the trailing-edge control surfaces are faired. Positive static stability requires that the nosedown pitching moment be minimized. This limits the use of positive aft camber and conflicts with the preceding deck angle requirement.

\section{Landing Approach Speed and Attitude}

BWB trailing-edge control surfaces cannot be used as flaps because the airplane has no tail to trim the resulting pitching moments. Trailing-edge surface deflection is set by trim requirements, rather than maximum lift. Therefore, the maximum lift coefficient of a BWB will be lower than that of a conventional configuration, and, hence, the wing loading of a BWB will be lower. Also, because there are no flaps, the BWB's maximum lift coefficient will occur at a relatively large angle of attack, and the flight attitude during approach is correspondinglyhigh.

\section{E. Buffet and Stal}

The BWB planform causes the outboard wing to be highly loaded. This puts pressure on the wing designerto increase both the outboard 
wing chord and washout, which degrades cruise performance. A leading-edgeslat is required outboard for low-speed stall protection. These issues apply to a conventional configuration, but they are exacerbated by the BWB planform.

\section{F. Power for Control Surface Actuation}

Tailless configurations have short moment arms for pitch and directional control, and, therefore, multiple, large, rapidly moving control surfaces are required. Trailing-edgedevices and winglet rudders are called on to perform a host of duties, including basic trim, control, pitch stability augmentation, and wing load alleviation. Because some of the control surfaces can perform multiple functions (e.g., outboard elevon/drag rudder offers pitch, roll, and yaw authority), control surface allocation becomes a critical issue. The mere size of the inboard control surfaces implies a constraint on the airfoil design to minimize hinge moments. Hinge moments are related to the scale of the control surface as follows: The area increases as the square of the scale, and, in turn, the moment increases with the cube of the scale. Once the hydraulic system is sized to meet the maximum hinge moment, the power requirement becomes a function of rate at which a control surface is moved.

If the BWB is designed with a negative static margin (unstable), it will require active flight control with a high bandwidth, and the control system power required may be prohibitive. Alternatively, designing the airplane to be stable at cruise requires front-loaded airfoils, washout, and limited (if any) aft camber. This implies a higher angle of attack, which, in turn, threatens the deck angle constraint.

\section{G. Manufacturing}

The aerodynamic solution to the design constraints just listed can readily result in a complex three-dimensional shape that would be difficult and expensive to produce. Therefore, the aerodynamicist must strive for smooth, simply curved surfaces that at the same time satisfy the challenging set of constraints just described.

\section{Initial Development and Feasibility}

A NASA/industry/university team was formed in 1994 to conduct a three-year study to demonstrate the technical and commer- cial feasibility of the BWB concept. McDonnell Douglas was the Program Manager, and the team members included NASA Langley Research Center, NASA John H. Glenn Research Center at Lewis Field, Stanford University, the University of Southern California, the University of Florida, and Clark-Atlanta University. The original 800-passenger 7000-n mile design mission was retained. This work is summarized in Ref. 3.

\section{A. Configuration Definition and Sizing}

This study began with a refined sizing of the initial BWB configuration (Fig. 6), where minimum takeoff gross weight (TOGW) was set as the figure of merit. Primary constraints included an 11,000$\mathrm{ft}$ takeoff field length, 150-kn approach speed, low-speed trimmed $C_{L \max }$ of 1.7 , and a cruise Mach number of 0.85 . Initial cruise altitude (ICA) was allowed to vary to obtain minimum TOGW, but with the requirement that the ICA be at least $35,000 \mathrm{ft}$. This yielded a trapezoidal wing of aspect ratio of 10 , with a corresponding span of $280 \mathrm{ft}$ and an area of $7840 \mathrm{ft}^{2}$. The resulting trapezoidal wing loading was on the order of $100 \mathrm{lb} / \mathrm{ft}^{2}$, substantially lower than the $150 \mathrm{lb} / \mathrm{ft}^{2}$ typical of modern subsonic transports. An explanation offered was that a significant portion of the trapezoidal wing is in effect hidden by the centerbody, and, therefore, the cost of trapezoidal wing area on airplane drag is reduced. This in turn allowed the airplane to optimize with a larger trapezoidal area to increase span with a relatively low cost on weight. A three-view and isometric of the resulting second-generation BWB is given in Fig. 9.

The double-deck BWB interior was configured with 10 150-in. wide passenger cabin bays, as shown in Fig. 10, with cargo compartments located outboard of the passenger bays and fuel in the wing, outboard of the cargo. Considerationsand constraintsincluded weight and balance, maximum offset of the passengers from the vehicle centerline (ride quality) and the external area of the cabin. Because this is the surface area of the pressure vessel, the extent of this area has a significant effect on the structural weight of the centerbody. The cabin partitions are in fact, wing ribs that are part of the primary structure. Windows were located in the leading edge on both decks, and the galleys and lavatories were located aft to help provide the passengers with an unobstructed forward view. Egress was via the main cabin doors in the leading edge, and through aft doors in the rear spar.

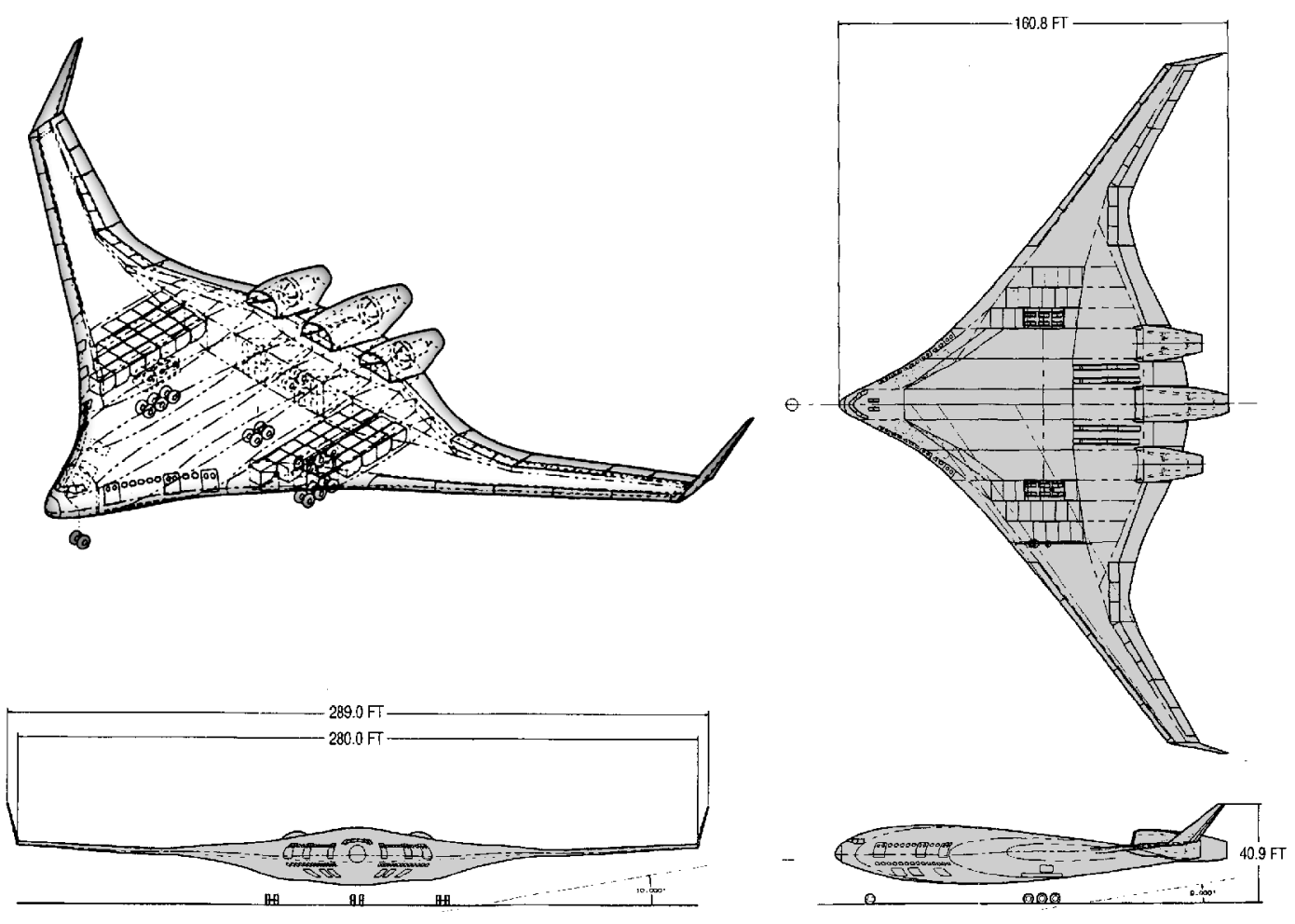

Fig. 9 Second-generation BWB. 


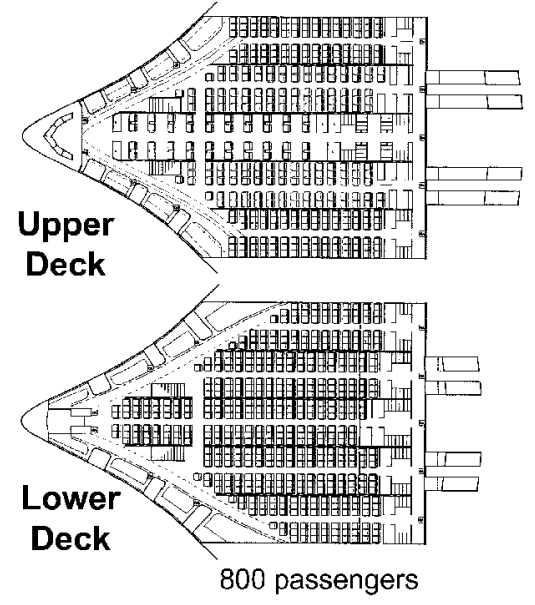

Fig. 10 Interior arrangement of passenger cabin.

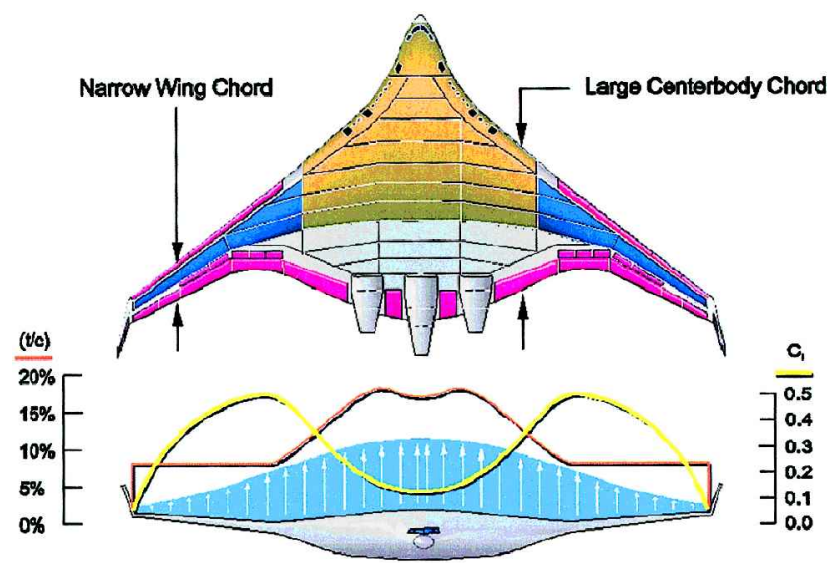

Fig. 11 Section lift coefficient and thickness-to-chord ratio variation with span.

\section{B. Aerodynamics}

Some insight into the aerodynamic design of the BWB is provided in Fig. 11, where the trade between wing chord, thickness, and lift coefficient is shown. The outboard wing is moderately loaded, similar to a conventional configuration, where drag is minimized with a balance between the wetted area and shock strength. Moving inboard, the centerbody, with its very large chord, calls for correspondingly lower section lift coefficients to maintain an elliptic spanload. The low section lift requirement allows the very thick airfoils for packaging the passenger compartment and trailing-edge reflex for pitch trim.

Navier-Stokes computational fluid dynamics (CFD) methodology in both the inverse design and direct solution modes was employed to define the final BWB geometry. A solution showing the pressure distribution at the midcruise condition is shown in Fig. 12. The typical shock on the outboard wing is smeared into a compression wave on the centerbody. The flow pattern on the centerbody remained essentially invariant with angle of attack, and flow separation is initiated in the kink region between the outboard wing and the centerbody. Outer wing flow remains attached, providing lateral control into the stall regime. Similarly, the flow over the centerbody remains attached and provides a nearly constant flow environment for the engine inlets. This flow behavior is a consequence of significant lateral flow on the centerbody that provides a three-dimensional relief of compressibility effects. However, the relief on the centerbody is traded for a transonically stressed flow environment in the kink region. This is the ideal spanwise location for the stall to begin, from a flight mechanics point of view: The ailerons remain effective, and pitch-up is avoided.

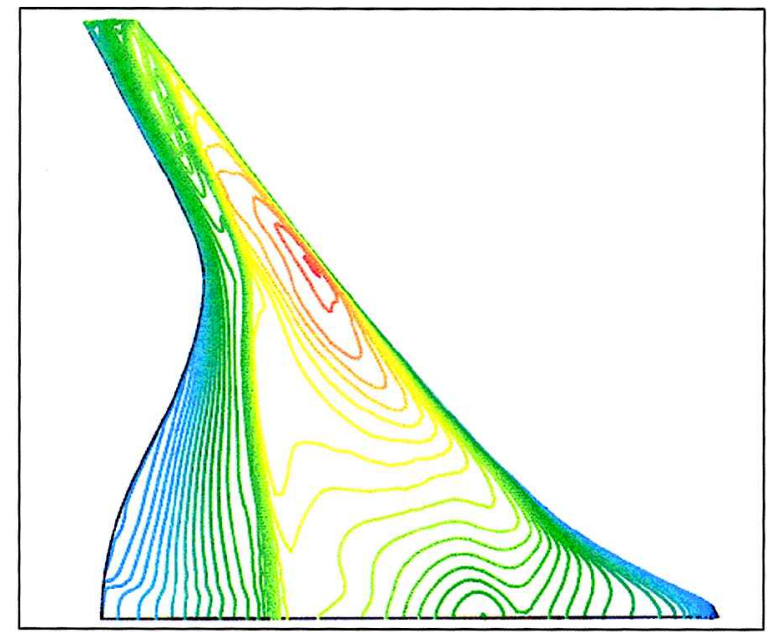

Fig. 12 Navier-Stokes computed upper surface pressure distributions.

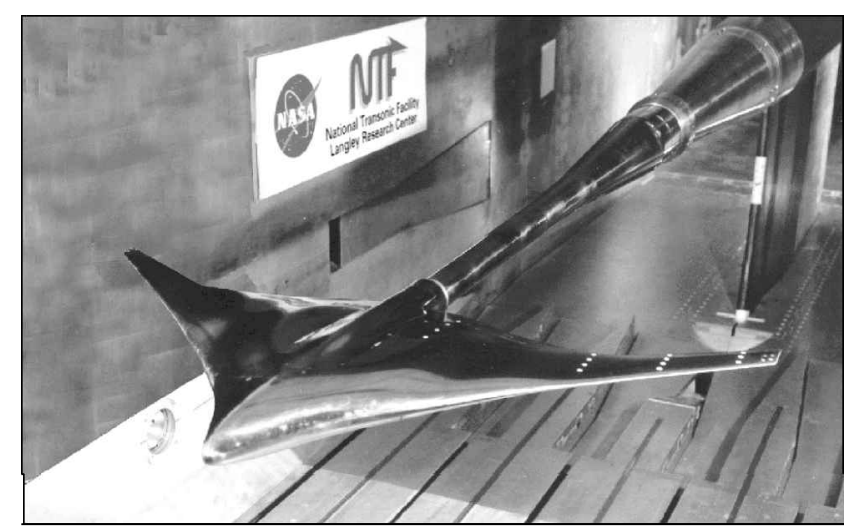

Fig. 13 BWB in the NASA LaRC NTF.

\section{Wind-Tunnel Tests}

Transonic and low-speed wind-tunnel tests of the BWB configuration (Fig. 9) were conducted at NASA Langley Research Center (LaRC) in the National Transonic Facility (NTF), and this represented an invaluable opportunity to test at close to the fullscale Reynolds number. Figure 13 shows the BWB model mounted in the tunnel, and NTF results are compared with CFD predictions in Fig. 14. Excellent agreement for lift, drag, and pitching moment, as well as wing pressure distributions, is shown, including up to and beyond buffet onset. A primary objective of the test was to establish the effectiveness of the current state-ofthe-art CFD methods for predicting the aerodynamic characteristics of a BWB airplane. The remarkable agreement indicated that CFD could be reliably utilized for the aerodynamic design and analysis.

A low-speed test of a powered $4 \%$ scale BWB was conducted in the NASA LaRC $14 \times 22$ foot wind tunnel(Fig. 15). Results verified trimmed $C_{L \text { max }}$ estimates, showed favorablestall characteristics, and showed excellent control power through stall. Power effects were found to be much smaller than expected.

\section{Stability and Control}

During development of the second-generation BWB, it was assumed and accepted that the airplane would be statically unstable to achieve high cruise efficiency $(L / D)$. Balance of the airplane was achieved by sliding the wing fore and aft on the centerbody, much like the procedure for a conventional configuration. However, this was clearly a more complex process due to the integrated nature of the BWB. The low effective wing loading meant that trailing-edge flaps would not be required, but a leading-edge slat on the outboard wing is required for the same reason as that on a conventional 
$C_{L}$

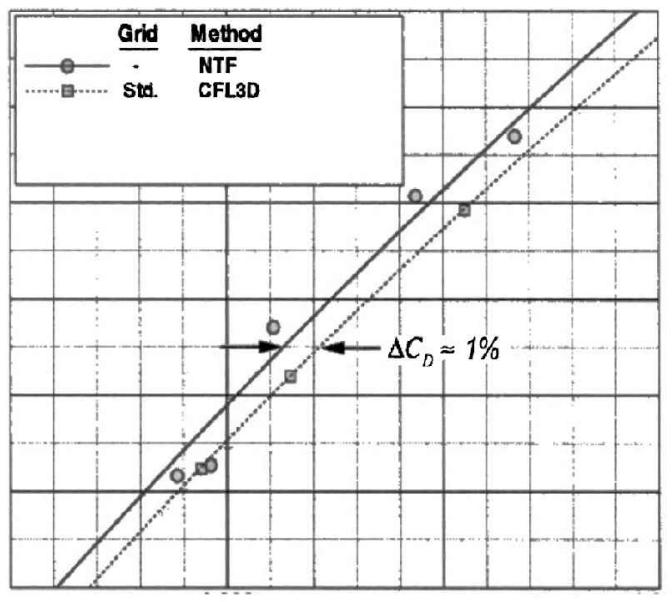

$\mathrm{C}_{\mathrm{D}}$

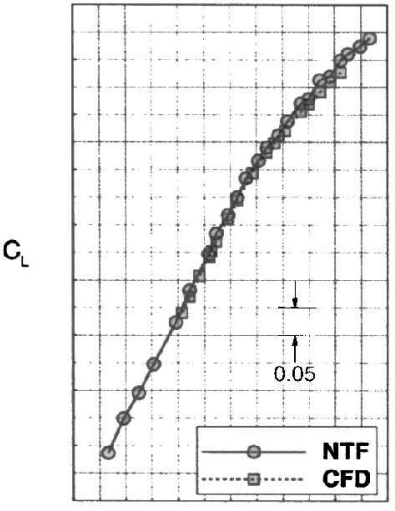

$\alpha$

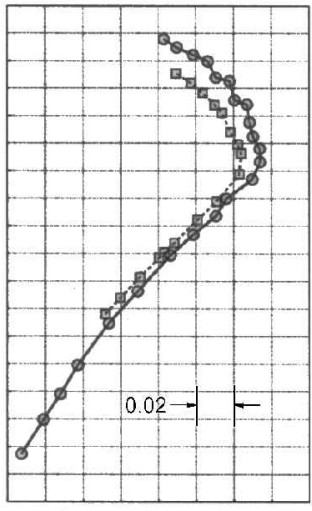

$\mathrm{C}_{\mathrm{M}}$
Fig. 14 Comparison of CFD predictions with NTF wind tunnel results.

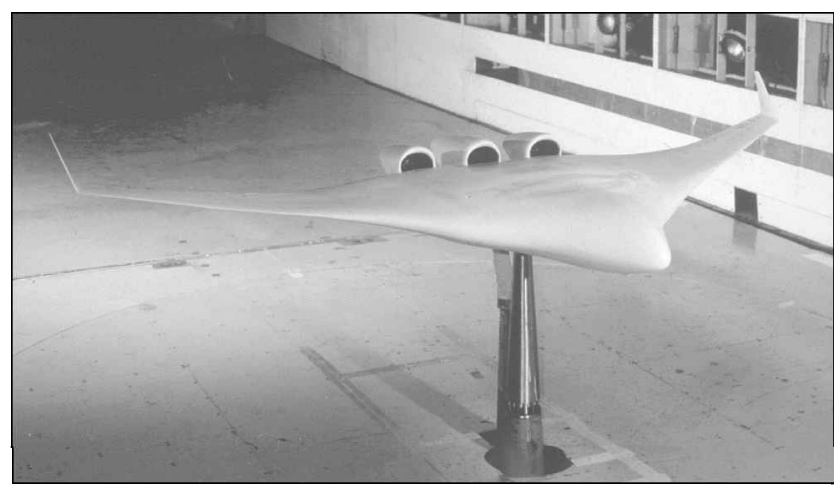

Fig. 15 Powered BWB model in the NASA LaRC $14 \times 22$ foot tunnel for low-speed test.

airplane. The simple-hinged trailing-edge control surfaces function as elevons. Flight-critical stability augmentation and envelope protection was considered a requirement.

The outboard elevons are the primary pitch and roll controls because they have the largest lever arm about the center of gravity. Figure 16 shows the pitch authority of the individual elevons, as well as the locus of their effective centers of pressure. Note that they yield relatively short lever arms about the center of gravity, and even shorter lever arms about the landing gear for takeoff rotation. However, total control power is substantial due to the full span of elevons. The winglets with rudders provide primary directional stability and control. For the low-speed engine-out condition, the outboard elevons become split drag rudders, similar to those on the B-2, as shown in Fig. 17.

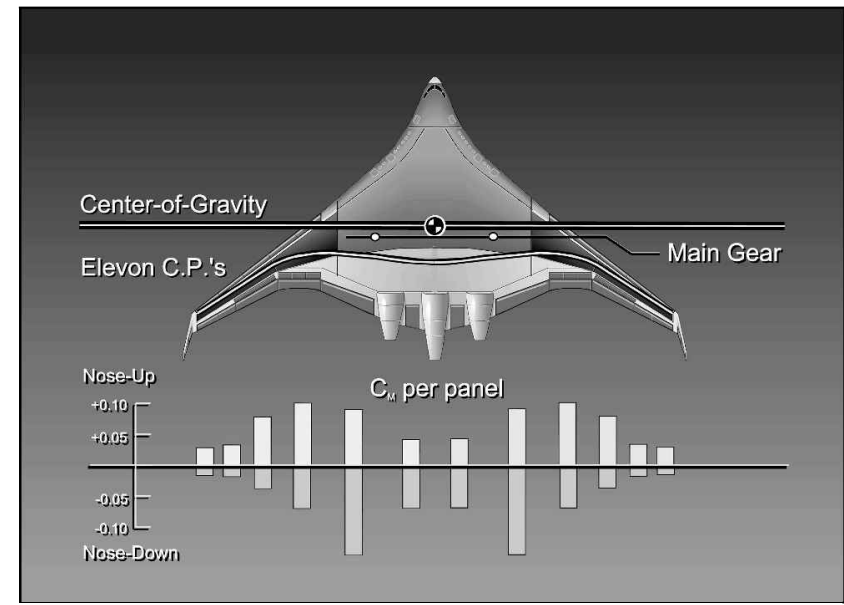

Fig. 16 Elevon effectiveness in pitch.

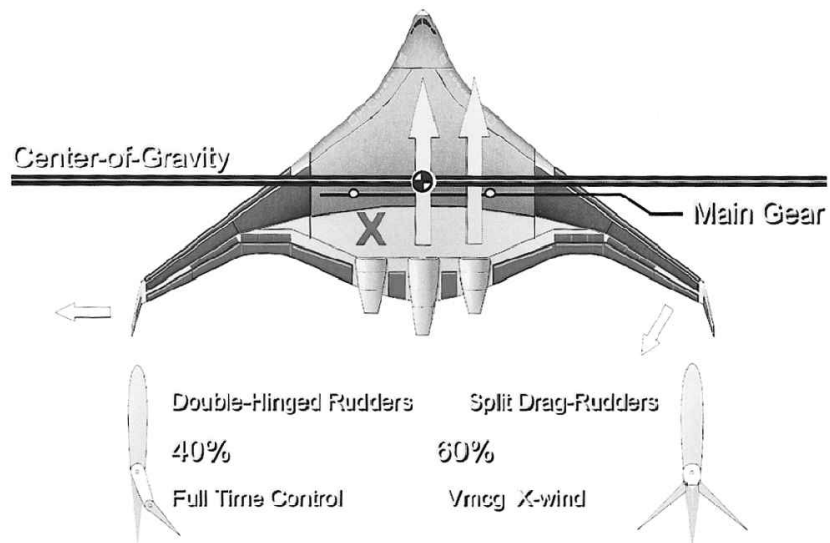

Fig. 17 Yaw control.

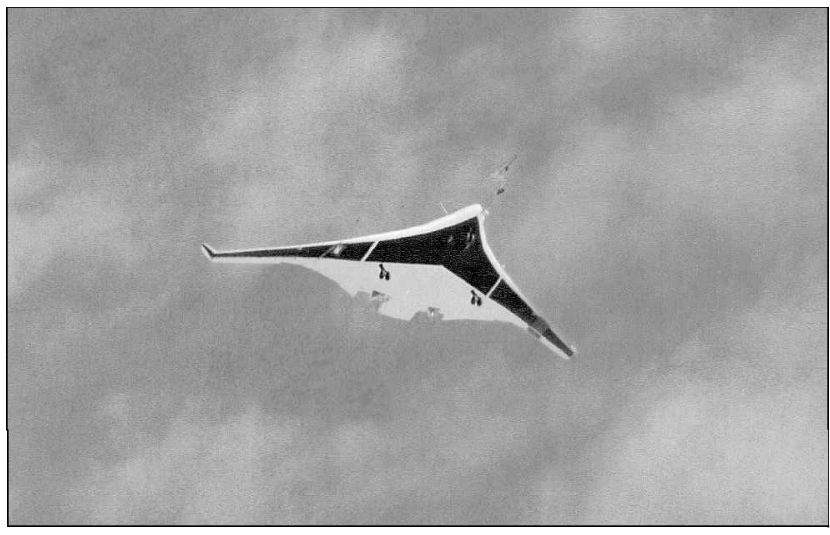

Fig. 18 Flight control testbed built by Stanford University.

\section{E. Flight Demonstrator}

Low-speed flight mechanics were explored with a $6 \%$ scale flight control testbed (Fig. 18), built at Stanford University under NASA sponsorship.Called the BWB-17, the airplane had a 17-ft wingspan, weighed $120 \mathrm{lb}$ and was powered by two $35-\mathrm{cm}^{3}$ two-strokeengines with propellers. The model was dynamically scaled to match the flight characteristics of the full-scale BWB. Stability augmentation was provided by an onboard computer, which also recorded flighttest parameters. The first flight of the BWB-17 took place on 29 July 1997, at El Mirage Dry Lake in California. Excellent handling qualities were demonstrated within the normal flight envelope. 

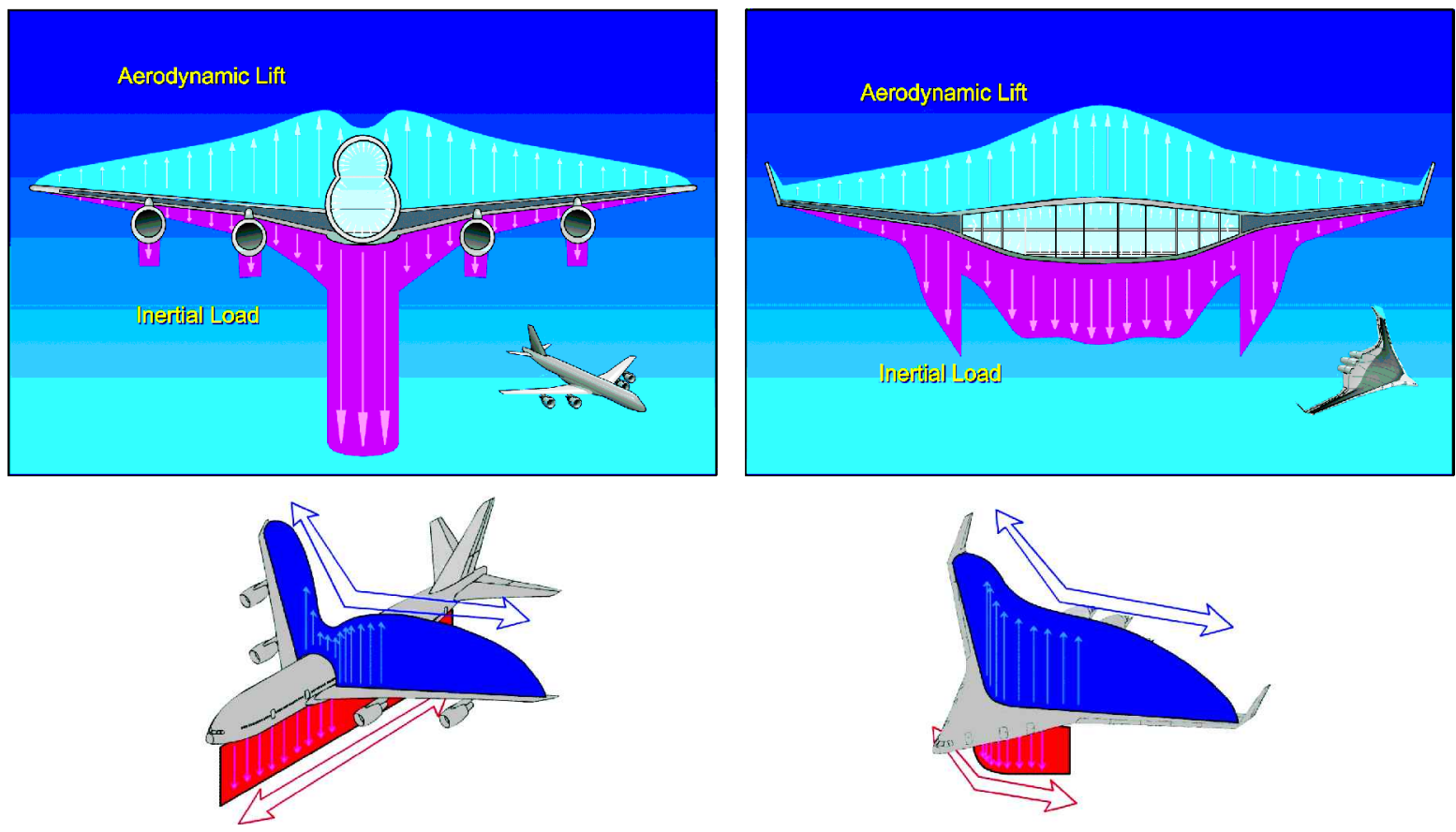

Fig. 19 Comparison of aerodynamic, inertial, and cabin pressure loads.

\section{F. Propulsion}

The aft engine location on the BWB offers the opportunity for ingestion of the boundary layer generated on the centerbody forward of the inlets. In principle, boundary-layer ingestion (BLI) can improve the propulsive efficiency by reducing ram drag. This assumes that an inlet can be designed that provides proper pressure recovery and uniform flow at the fan face of the engine. Alternatively, the boundary layer can be diverted around the sides of the inlets, but this implies dumping low-energy air into an already transonically stressed pressure recovery region. Simply mounting the engines on pylons is another option, but increased wetted area and weight plus nosedown thrust moment are detractors from this installation.

NASA-sponsored studies of the BLI concept were conducted at the University of Southern California (USC) and at Stanford University. At USC, a wind-tunnelsimulation was created with an upstream flat plate to generate the boundary layer and various duct geometries, leading to a station representing the fan face of the engine, where the flow quality was evaluated. Results indicated that proper configurations of vortex generators could provide a reasonably uniform flow at the fan face with acceptable pressure recovery. These results were utilized at Stanford University to help guide a theoretical multidisciplinary optimization study of the BWB engine inlet concept. Navier-Stokes based CFD was used to represent the centerbody and inlet flowfield, and engine performance was modeled as a function of the flow quality at the fan face. The optimizer indicated that minimum fuel burn was obtained with the engine swallowing the boundary layer, as opposed to diverting the boundary layer around the inlet. ${ }^{4,5}$

The aft engine location of the BWB allows for several installation options; however, integration affects all of the basic disciplines. Uniquely for a BWB, there is no explicit penalty for the centerline engine of a three-engineinstallation. Candidate installationconcepts include podded with pylon, upper or lower surface inlet with S-duct, BLI, or diverter; and, finally, the engine count itself. Airplanes were sized for 12 differentcombinations with appropriategains and losses for inlet recovery and distortion, wetted area drag (including the adjustment for BLI), weight, and thrust moment. The figure of merit was the TOGW. Additional considerationsincluded ditching, emergency egress, foreign object damage (FOD), noise, reverse thrust, and maintainability. Lower surface inlets were discarded on the basis of FOD and ditching. A three-engine configuration with upper surface BLI inlets and S-ducts to the engines was selected. If BLI did not prove practical, boundary-layer diverters were assumed to be the default.

\section{G. Structure}

The unique element of the BWB structure is the centerbody. As the passenger cabin, it must carry the pressure load in bending, and as a wing it must carry the wing bending load. A comparison of the structural loading of a BWB with that of a conventional configuration is given in Fig. 19. Peak wing bending moment and shear for the BWB is on the order of one-half of that of the conventional configuration. The primary challenge was to develop a centerbody structural concept to absorb the cabin pressure load. Unlike a wing, which rarely experiences its design load (typically via a 2.5-g gust), the passenger cabin sees its design pressure load on every flight. Thus, on the basis of fatigue alone, the centerbody should be built from composites due to their comparative immunity to fatigue.

The overall structural concept selected for this NASA-sponsored study is shown in Fig. 20. Outboard wing structure is essentially conventional and was assumed to be composite. The centerbody structural shell was based on two candidate concepts: a 5-in. thick sandwich, or a skin plus 5-in. deep hat-section stringers. A global finite element model was analyzed for the combined pressure and wing bending loads on the centerbody. Cabin skin deflection due to a two times pressure load is shown in Fig. 21.

\section{H. Safety and Environmental}

The BWB offers several inherent safety features that are unique to the configuration. An uncontained engine failure can not impact the pressure vessel, fuel tanks, or systems. The pressure vessel itself is unusually robust because its structure has been sized to carry both the pressure loads and wing bending loads, and, consequently, its crashworthiness should be substantial.

Environmentally, the BWB naturally offers a low acoustic signature, before any specific acoustic treatment. The centerbody shields forward radiated fan nose, and engine exhaust noise is not reflected from the lower surface of the wing. Airframe noise is reduced by the absence of a slotted flap trailing-edge high-lift system. Engine emissions are reduced in direct proportion to the reduced fuel burn per seat mile described hereafter. 


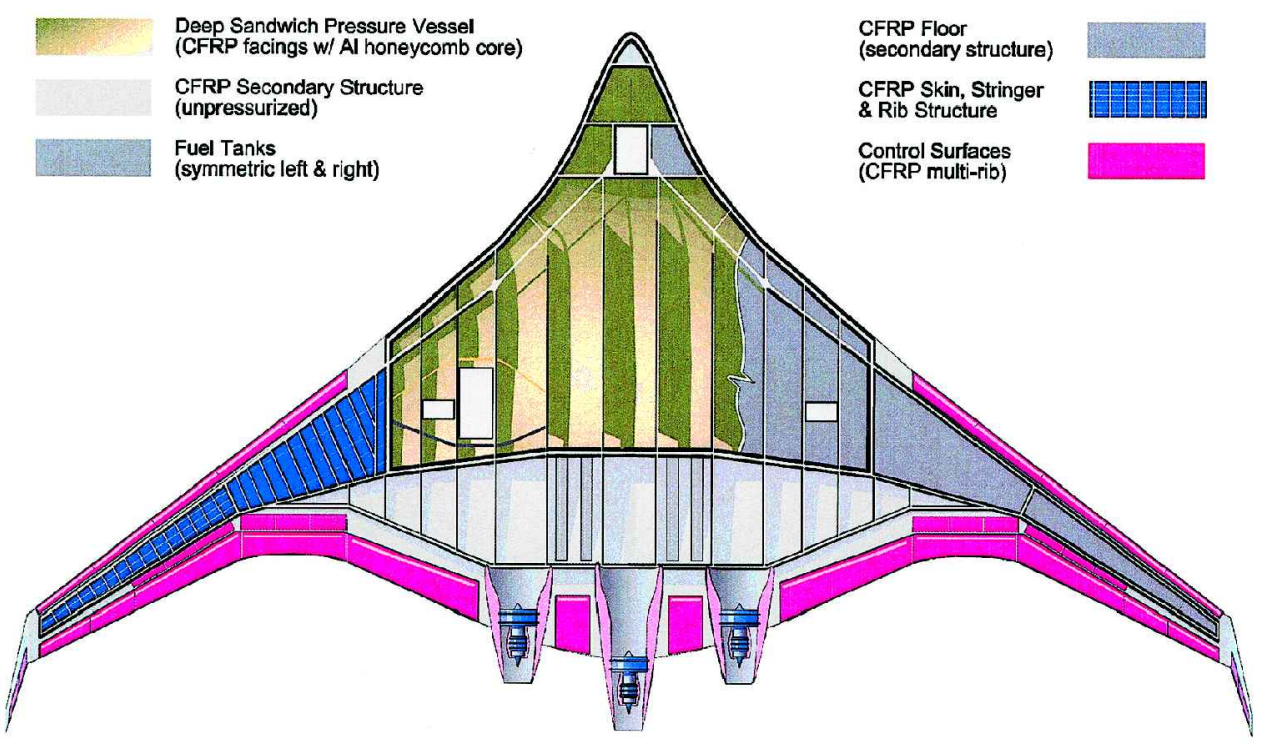

Fig. 20 Structural layout of second-generation BWB.

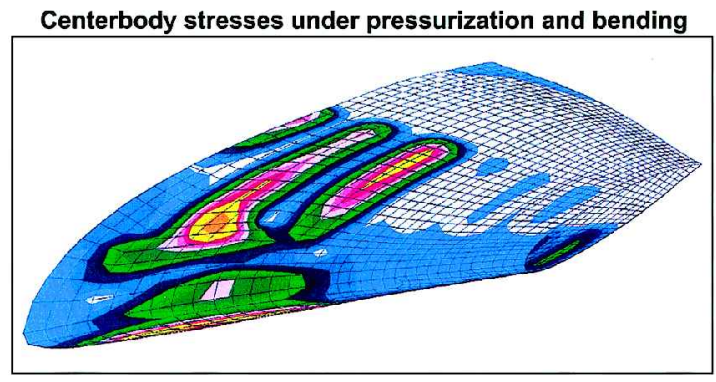

Fig. 21 Finite element model solution showing exaggerated cabin skin deflection at two times pressure.

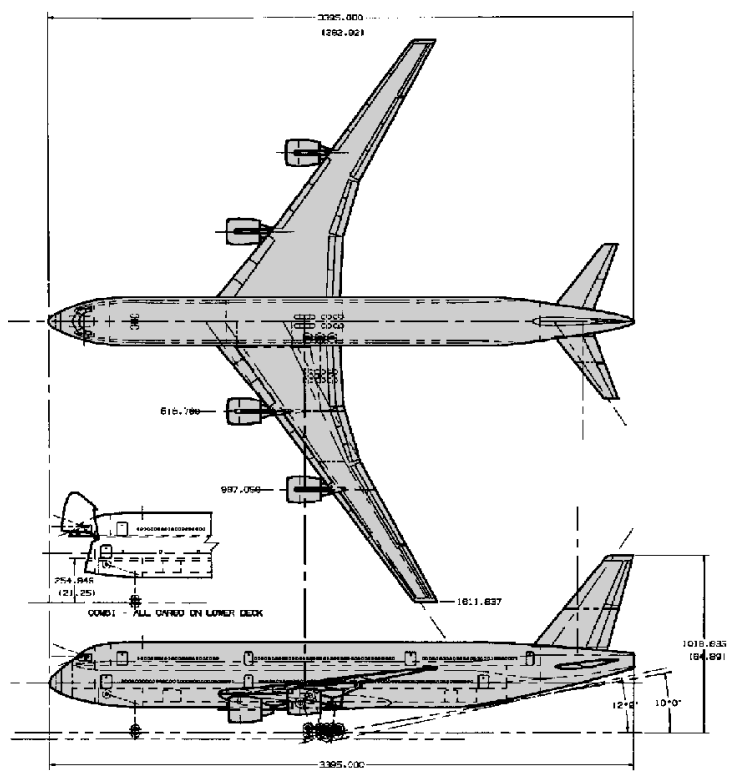

Fig. 22 Conventional baseline configuration.

\section{Performance}

A proper evaluation of the BWB concept required that a conventional subsonic transport be sized to the same design mission, employing the same composite structure technology and the same class of advanced technology engines. A two-view of the conventional baseline is shown in Fig. 22, and Table 1 compares the performance of the BWB with the baseline. In addition to the significant reduction in weight, the BWB requires one less 60,000 -lb-class engine,
Table 1 Performance comparison of the second-generation BWB with the conventional baseline airplane

\begin{tabular}{lcc}
\hline \hline Model & BWB & Conventional \\
\hline Passengers & 800 & 800 \\
Range, $\mathrm{n}$ mile & 7,000 & 7,000 \\
MTOGW, lb & 823,000 & 970,000 \\
OEW, lb & 412,000 & 470,000 \\
Fuel burned, lb & 213,000 & 294,000 \\
$L / D$ at cruise & 23 & 19 \\
Thrust, total lb & $3 \times 61,600$ & $4 \times 63,600$ \\
\hline \hline
\end{tabular}

Table 2 Design requirements and objectives for the Boeing BWB-450 baseline

\begin{tabular}{|c|c|}
\hline Parameter & Value \\
\hline Payload & $\begin{array}{l}468 \text { passengers }+ \text { baggage, } \\
\text { three-class arrangement }\end{array}$ \\
\hline Design range & $7750 \mathrm{n}$ mile \\
\hline Crew & Standard two-man crew \\
\hline Reserves & $\begin{array}{l}\text { International reserve fuel } \\
\text { Fuel equal to } 5 \% \text { of block fuel } \\
200 \mathrm{n} \text { mile diversion to alternate airport } \\
\text { One-half hour hold at } 1500 \mathrm{ft} \\
\text { at holding speed }\end{array}$ \\
\hline Constraints & $\begin{array}{l}11,000-\mathrm{ft} \text { field length } \\
140-\mathrm{kn} \text { approach speed } \\
2.7^{\circ} \text { segment climb gradient } \\
300-\mathrm{ft} / \mathrm{min} \text { excess power at top of climb }\end{array}$ \\
\hline
\end{tabular}

and its fuel burn per seat mile is $27 \%$ lower. Given that the configuration was the only technical difference in these two airplanes, the potential for the BWB concept was regarded as remarkable.

\section{Boeing BWB-450 Baseline Airplane}

The three-year study just described demonstrated the feasibility and performance potential of the BWB. Based on these results and predictions, it was decided to initiate a Boeing preliminary design study of a BWB transport. The 800-passenger 7000-n mile design mission of the feasibility studies was deemed inappropriate for the in-house evaluation of the BWB. Comparisons with existing airplanes and airplanes of other preliminary design studies would not be possible, and a payload of 800 passengers was simply beyond market forecast data.

\section{A. Design Requirements and Objectives}

The design mission selected for the baseline BWB is given in Table 2. Although distinct from existing airplanes, this specification 


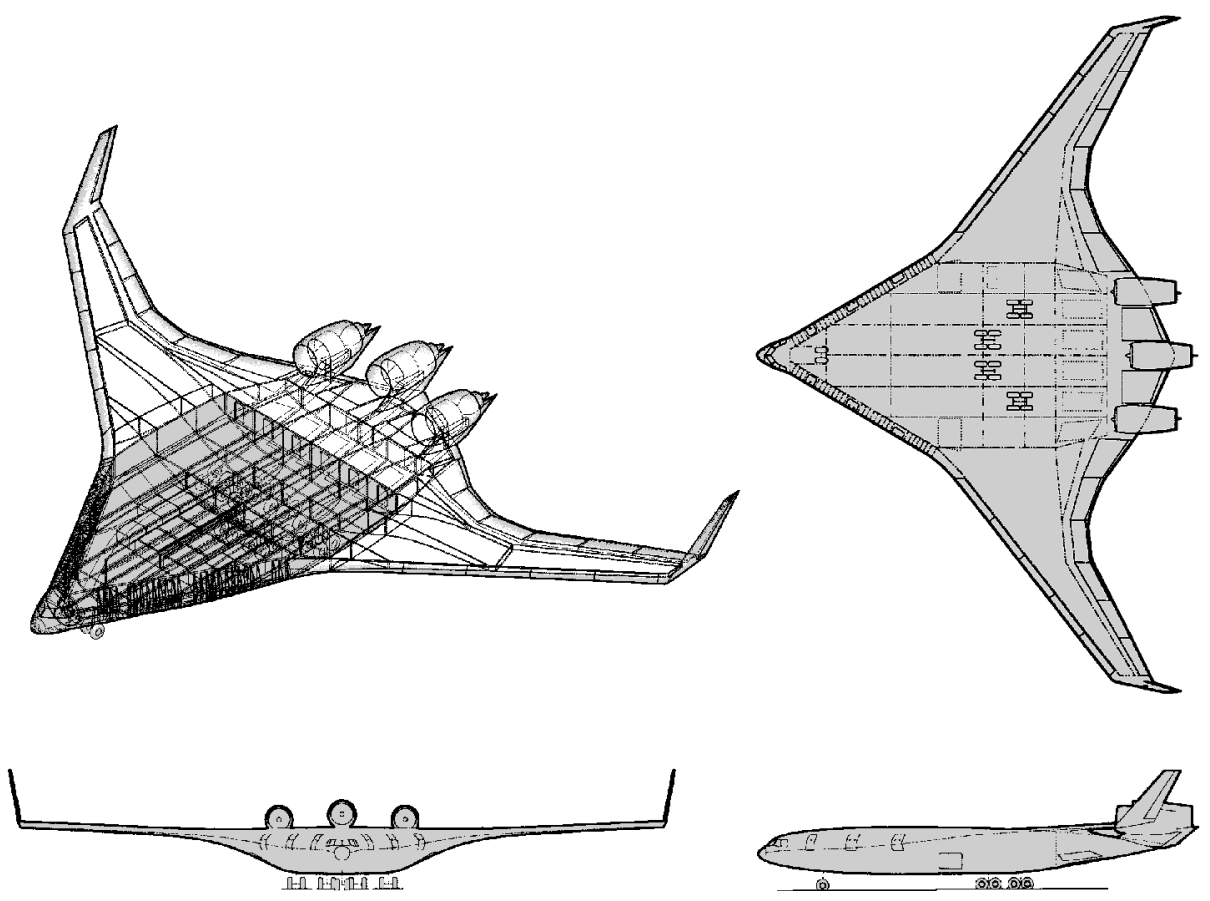

Fig. 23 Boeing BWB-450 baseline.

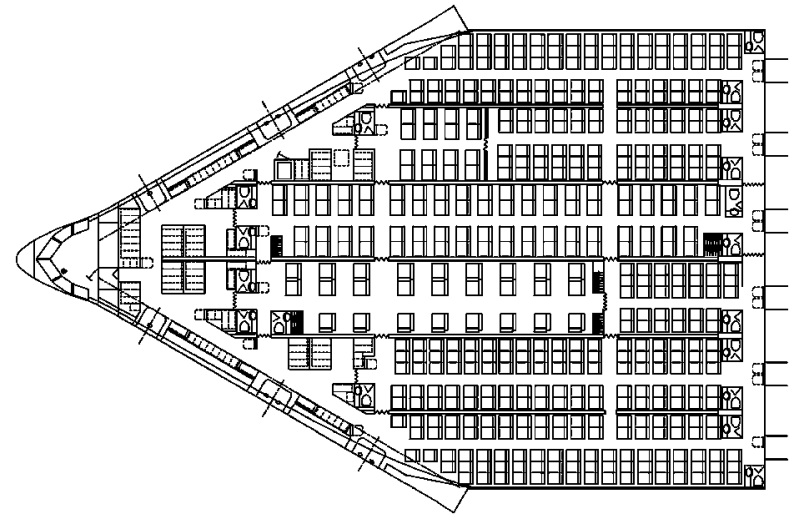

Fig. 24 Three-class interior arrangement.

offered the opportunity for some comparison of the resulting BWB with the B747, A340, and the then-pending A3XX. Initial specification of 450 passengers (hence, the designation BWB-450) was considered nominal, and the final passenger count would be established as the airplane was configured and sized. Also, although somewhat ignored in the earlier studies, airport compatibility requirements were enforced for the baseline BWB, in particular, the wingspan limit of $262 \mathrm{ft}(80 \mathrm{~m})$.

\section{B. Configuration of the Boeing BWB-450 Baseline}

Per the requirements just listed and the optimization procedure described hereafter, the baseline BWB shown in Fig. 23 was created. Minimum TOGW was the objective function. Trapezoidal aspect ratio is 7.55, down substantially from the earlier BWBs, and the wingspan of $249 \mathrm{ft}$ fits easily within the $80-\mathrm{m}$ box for Class VI airports. Passenger count is 478 , based on three-class international rules. Figure 24 shows the interior arrangement, and Fig. 25 shows representativecross sections of the centerbody. The entire passenger cabin is on the upper deck, and cargo is carried on the lower deck, similar to conventionaltransports. All of the payload is located ahead of the rear spar. Crashworthiness contributed to this arrangement.

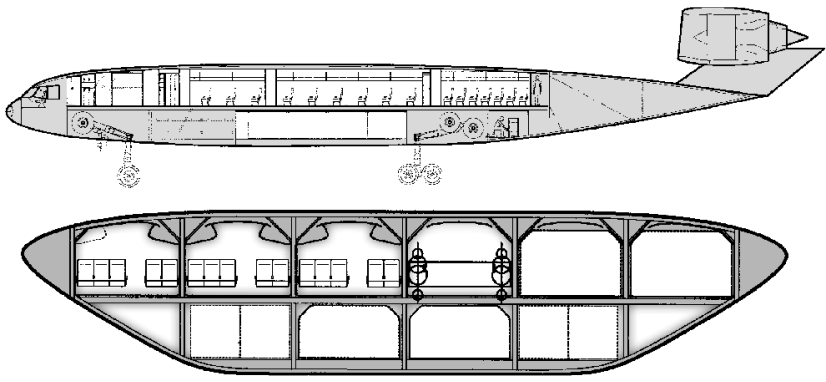

Fig. 25 Centerbody interior cross sections.

\section{Multidisciplinary Design Optimization}

As described, the BWB is an integrated configuration where the interaction of the basic disciplines is unusually strong. Conventional design intuition and approach are challenged, if not overwhelmed, when faced with sizing and optimizing the BWB airplane. The method of Ref. 6, a pragmatic and functional multidisciplinary airplane design optimization code, was adopted. This work has evolved into a Boeing proprietary code called WingMOD. In the case of the BWB, the airplane is defined by an initial planform and a stack of airfoils whose section characteristics, for example, moment coefficient $c_{\text {mac }}$ and drag coefficient $c_{d}$, are known as a function of thickness-to-chord ratio $t / c$, section lift coefficient $c_{l}$ and Mach number. WingMOD then models the airplane with a vortex-lattice code and monocoque beam analysis, coupled to give static aeroelastic loads. The model is trimmed at several flight conditions to obtain load and induced drag data. Profile and compressibility drag are then evaluated at stations across the span, based on the airfoil section properties and the vortex-lattice solution. Structural weight is calculated from the maximum elastic loads encountered through a range of flight conditions, including maneuver and vertical and lateral gusts. The structure is sized based on bending strength and buckling stability considerations. Maximum lift is evaluated by the use of a critical section method that declares the wing to be at its maximum useable lift when any spanwise airfoil section reaches its maximum lift coefficient.

Figure 26 shows a small portion of an example WingMOD solution for the baseline BWB-450. The procedure begins with the manual definition of a baseline design (not to be confused with the 


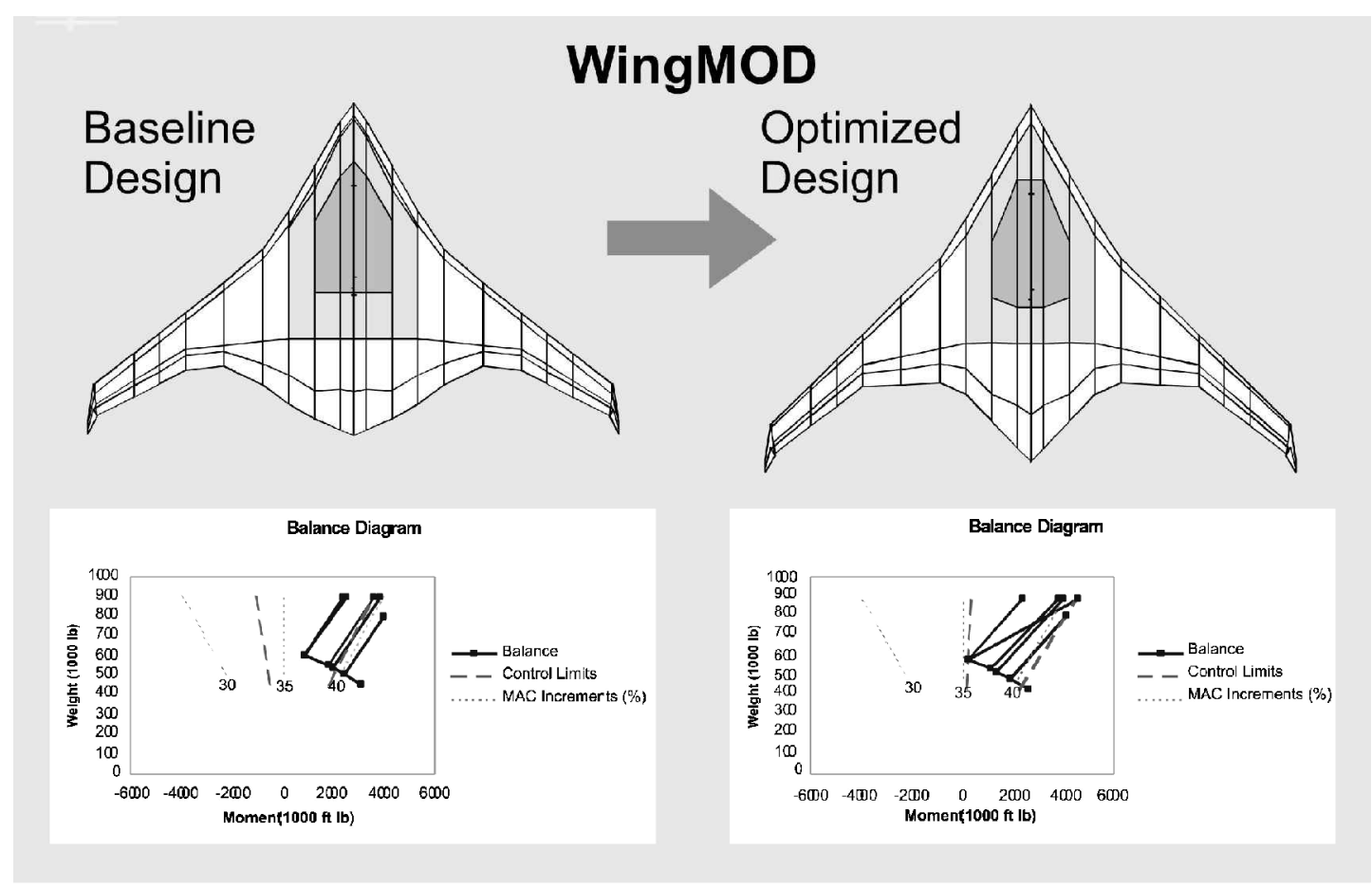

Fig. 26 Example WingMOD solution for the BWB baseline.

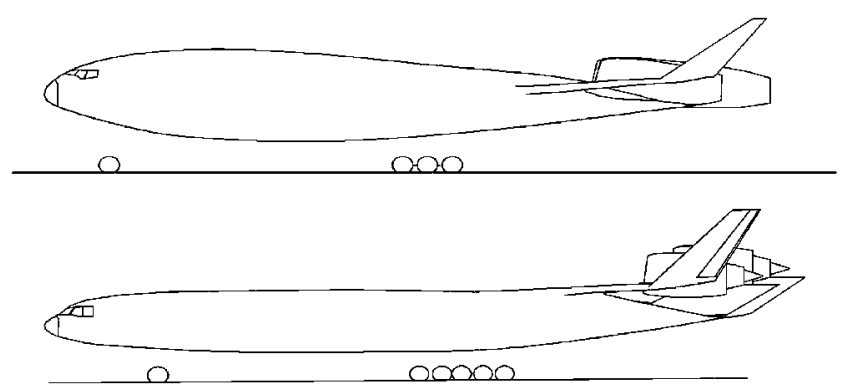

Fig. 27 Comparison of centerbody profiles of the second-generation BWB with the Boeing baseline BWB.

term "baseline BWB"). Subject to the mission definition and constraints (e.g., range, takeoff field length, approach speed, interior volume, etc.), WingMOD provides the definition of the minimum TOGW configuration that meets the mission while satisfying all constraints. Put another way, the optimized airplane design is closed and meets all design mission requirements with minimum TOGW.

\section{Aerodynamics}

Aerodynamic design of the BWB-450 was coupled with WingMOD to obtain the final aerodynamic definition (outer mold line). Definition of the airfoil stack was a key element to this approach. A new class of transonic airfoils for the centerbody was designed based on constraints of cross-sectionalarea required to hold passengers, baggage, and cargo properly. The new airfoils tightly package the payload without a drag penalty. More significantly, the new airfoils smoothed and flattened the geometry to simplify manufacture. Figure 27 shows a comparison of the centerbody profile of the second-generation BWB with the Boeing BWB-450.

The planformalso underwent significant change from the secondgeneration BWB, as shown in Fig. 28, which also gives the comparison where both planforms are scaled to the same wingspan. Airfoil chords have been increased on both the outer wing and the centerbody. Buffet onset level and characteristics primarily drove outboard chord increase. Figure 29 compares the lift curves $\left(C_{L}\right.$ vs $\alpha)$ and lift vs pitching moment curves $\left(C_{L}\right.$ vs $\left.C_{M}\right)$ for the BWB-450

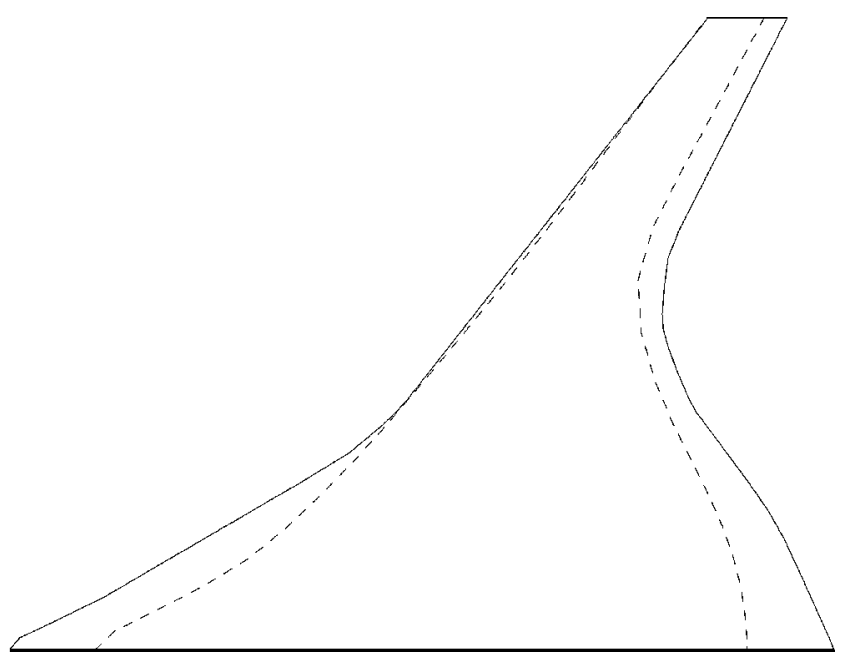

Fig. 28 Planform comparisons of the second-generation $B W B$ with the Boeing Baseline BWB: — tion (scaled).

and the second-generation BWB. If the buffet $C_{L}$ is defined at the break in the $C_{L}$ vs $C_{M}$ curve, the improvement of the new planform is apparent. Compared to the earlier design, there is almost twice the margin between midcruise $C_{L}, 1.3 \mathrm{~g}$-buffet, and buffet itself. Centerbody chords were increased to reduce their thickness-to-chord and afterbody closure angles. Although this increased wetted area, the increased friction drag was more than offset by a reduction in pressure drag. Inboard elevon effectiveness was also improved. Aerodynamic design of the BWB is discussed in more detail in Ref. 7.

\section{E. Stability and Control}

The planform, airfoilstack, and twist distributionof the BWB-450 resolves the longitudinal trim problem with more efficiency than most flying-wing airplanes. Historically, flying wings have been trimmed by sweeping the wing and downloading the wingtips. Whereas this approach allows the wingtips to functionally serve as a 

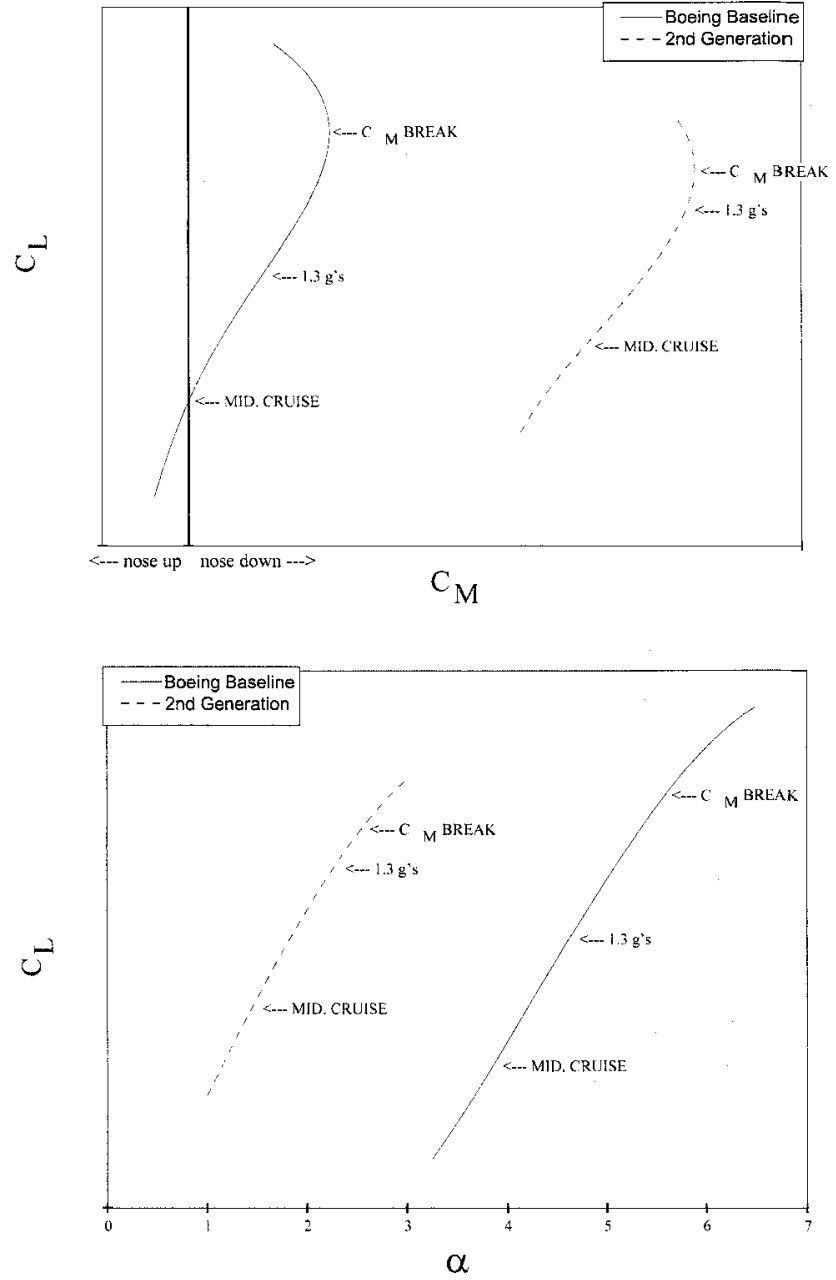

Fig. 29 Comparison of lift and moment curves of the secondgeneration BWB with the Boeing Baseline BWB.

horizontal tail, it imposes a significant induced drag penalty. The effective aerodynamic wingspan is less than the physicalspan, and this penalty is a primary reason that flying-wing airplanes have failed to live up to their performance potential. As described earlier, the firstand second-generationBWB were allowed to have significantly negative static margins to preserve a near-elliptic spanload. The BWB450 has been trimmed by a careful distribution of spanload coupled with a judicious application of wing washout. The result is a flyingwing airplane that is trimmed at a stable center of gravity $(+5 \%$ static margin) with all control surfaces faired, and with no induced drag penalty. Setting this design condition at the midcruise point results in a trim drag of one count at start of cruise (high $C_{L}$ ), and a one-half count of trim drag at end of cruise (lower $C_{L}$ ).

\section{F. Propulsion}

The second-generation BWB assumed boundary-layeringestion for both the engine installation and the performance estimate. For the BWB-450 it was decided to reduce the technology risk by examining the performance of both boundary-layerdiverters and simple podded engines on pylons. Navier-Stokes based CFD was used to evaluate these options. To the extent they were studied, the diverters showed an unacceptable drag increase due to the low energy of the diverted boundary layer, plus its interaction with the pressure recovery region of the aft centerbody. Alternatively, the initial modeling of the podded engines on pylonsindicated that the increasein wetted area was only $4 \%$ compared to the diverted configuration. The thrust moment, although undesirable, was deemed acceptable. A thorough CFD-based design and analysis study showed that an interferencefree podded engine and pylon installation could be achieved, and the net drag penalty was simply due to the wetted area increase. There-

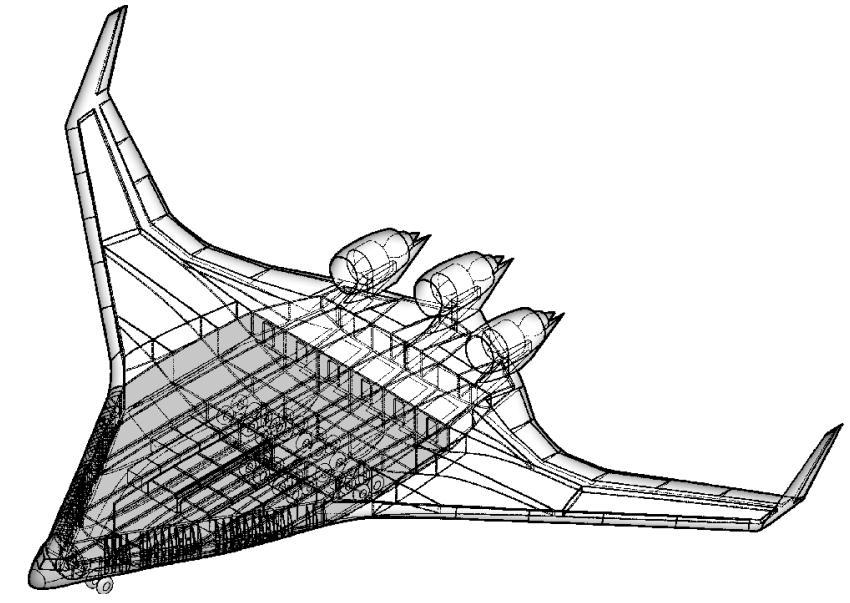

Fig. 30 Centerbody structural concept.

fore, podded engines on pylons became the selected installation for the baseline BWB.

\section{G. Structure}

The BWB structure is divided into two main components: the centerbody and the outer wings. The structure of the outer wings is similar to that of a conventional transport. The centerbody is subdivided into the forward pressure vessel and the unpressurized afterbody. Development of the structure for the centerbody and its pressure vessel was approached by defining and comparing several concepts. Weight and cost were the primary figures of merit. One of the most viable concepts was based on a skin/stringer outer surface structure where the stringers are on the order of 5-6 in. deep. The internal ribs have $Y$ braces where they meet the skin, to reduce the bending moment on the skin created by the internal pressure. (This could be regarded as a structural analog to the earlier concept of an arched pressure membrane.) As shown in Fig. 30, the complete centerbody pressure vessel is composed of the upper and lower surface panels, the rounded leading edge (which also functions as the front spar), the rear main spar, the outer ribs (which must also carry the cabin pressure load in bending), and the internal ribs (which carry the cabin pressure load in tension). The cabin floor simply supports the payload and does not carry wing bending loads. Finite element analyses have been used to develop and verify this structural concept and its weight. The final result is an unusually rugged passenger cabin that weighs little more than a conventional fuselage.

Studies to date have assumed composite material for the majority of the BWB primary structure. The outer wings could readily be fabricated from aluminum with the typical $20 \%$ weight penalty. However, as mentioned earlier, the weight penalty for using aluminum for the centerbody structure would be larger. The design cabin pressure load is experienced on every flight, and, thus, fatigue becomes the design condition. Because cabin pressure loads are taken in bending, the margin required for aluminum could be prohibitive, whereas composites are essentially immune to fatigue and, hence, would suffer no penalty.

Figure 31 shows a comparison of the structural weight fractions of a BWB and a conventional configuration, both sized for the same mission and both assuming the same composite structure technology. Although the centerbody structure of the BWB is heavier than that of a conventional fuselage, the weight (OEW) of the complete configuration of the BWB is markedly lighter.

\section{H. Performance}

A performance comparison of the Boeing BWB- 450 with the Airbus A380-700 is given in Fig. 32. Both airplanes are compared for a payload of approximately 480 passengers and a range of $8700 \mathrm{n}$ mile. (A380 data are from an Airbus brochure.) Probably the most striking result is the BWB's $32 \%$ lower fuel burn per seat. 


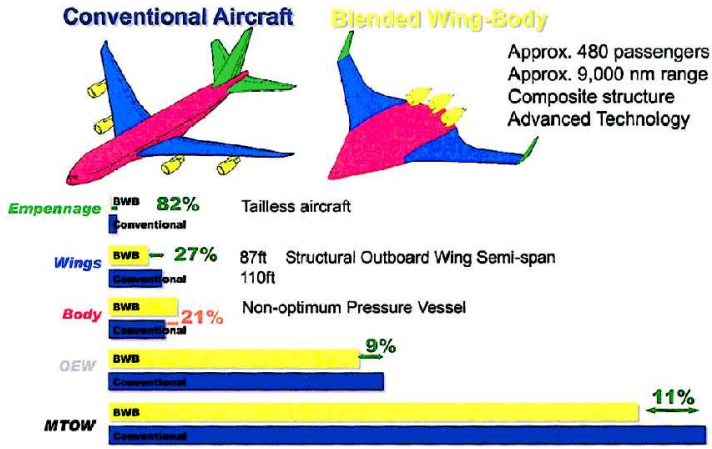

Fig. 31 Comparison of structural weight fractions from a BWB and a conventional configuration.
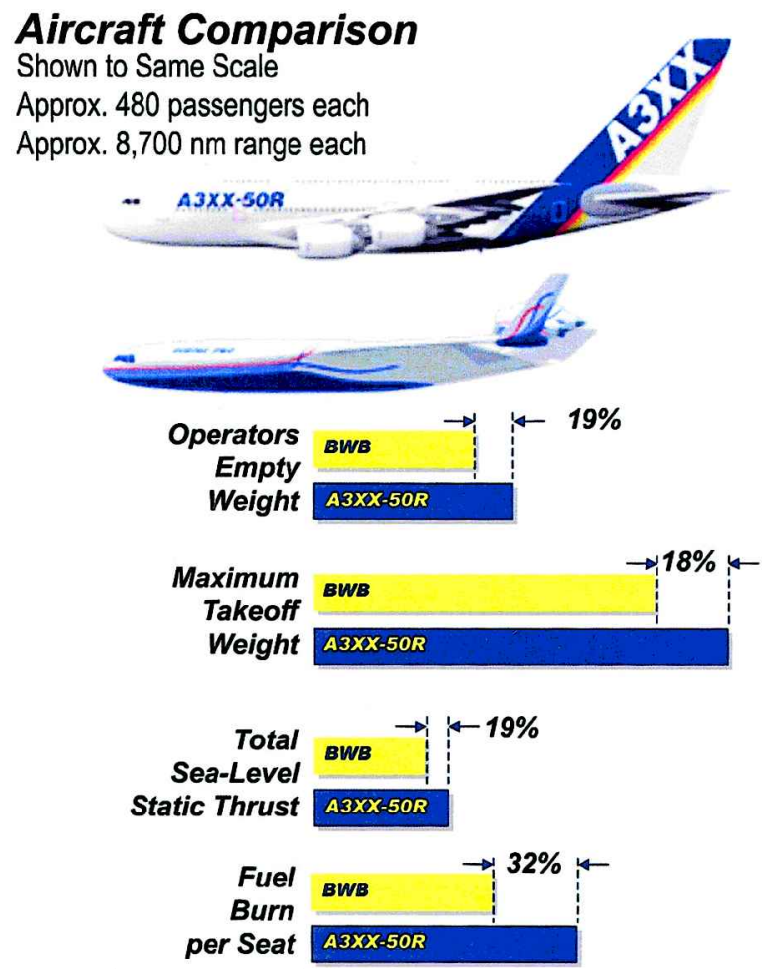

Fig. 32 Performance comparison of the BWB-450 with the A380-700.

Both airplanes are using equivalent technology engines of similar thrust levels; however, the A380-700 requires four, whereas the BWB-450 requires three. The primary structure of the A380-700 is aluminum, with the exception of the outer wing panels, which are understood to be composite. The BWB-450 primary structure is essentially all composite. A comparison of the BWB-450 cabin volume with that of the A380-700 is shown in Fig. 33.

\section{Environment}

The Boeing BWB-450 offers the potential for a significant reduction in environmentalemissions and noise. Lower total installed thrust and lower fuel burn imply an equivalent reduction in engine emissions, under the assumption of the same engine technology. As discussed earlier, the forward-radiated fan noise is shielded by the vast centerbody, and engine exhaust noise is not reflected by the lower surface of the wing. The lower thrust loading itself implies lower noise. There are no slotted trailing-edge flaps, so a major source of airframe noise is eliminated. Thus, before any specific acoustic treatment, the BWB offers a significant reduction in noise.

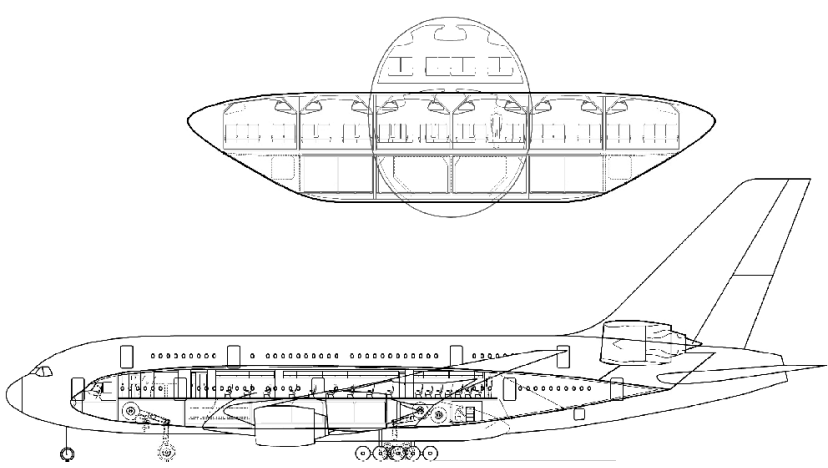

Fig. 33 Interior volume comparison of the BWB-450 with the A380700 .

\section{Unique Opportunities and Challenges of the BWB Configuration}

Creation of the original BWB was motivated by a search for an airplane configuration that could offer improved efficiency over the classic tube and wing. Takeoff weight and fuel burn were the primary figures of merit, and the BWB concept has shown substantial reductions in these two performance parameters, as described earlier. However, the BWB configuration offers some unique opportunities that were neither envisioned nor planned during its original creation in 1993. Three of these are described hereafter.

\section{A. Manufacturing Part Count}

The BWB is simply a big wing with an integrated fuselage and no empennage, save the winglets/verticals. There are no complex wingfuselage and fuselage-empennage joints of highly loaded structures at $90 \mathrm{deg}$ to one another, and there are no fillets. All trailing-edge control surfaces are simple hinged with no track motion, and there are no spoilers. This manifests a substantial reduction (on the order of $30 \%$ ) in the number of parts when compared to a conventional configuration. A similar reduction in manufacturing recurring cost is implied.

\section{B. Family and Growth}

Reference 2, which describes the early development of the BWB, contains the remark; "Any change such as wing area or cabin volume implies a complete reconfiguration. Stretching is not in the vocabulary." That was the thought at the time. As development progressed, it was discovered that the BWB concept could be ideal for a family of airplanes with the potential for substantial commonality among its members. Here stretching takes place laterally (spanwise), as opposed to longitudinally. Passenger capacity can be increased by adding a central bay to the centerbody and vice versa. Wing area and span automatically increase or decrease appropriately with passenger capacity, a quality not offered by the longitudinal stretching of a conventional airplane.

To achieve this growth capability, the aerodynamic outer mold lines of all of the family members must remain smooth and provide proper aerodynamic performance. In addition, all of the airplanes must be trimmed and balanced. Geometrically, this has been achieved by essentially defining the centerbody as a ruled surface in the spanwise direction. In turn, this allows the definition of several airplanes ranging, for example, from 250 to 550 passengers, as shown in Fig. 34. Centerbody cabins are composed of combinations of two or more distinct cabins (shown in green, yellow, and orange). The outer wing panels and nose sections (shown in blue) are of identical geometry for all family members. Distinct to each airplane are the transition section aft of the nose, the aft centerbody, and engines (shown in gray). Nose gear and outer main gear could be common for all family members, with a center main gear of varying capacity added where required.

A representative set of the airplane family has been examined in depth to establish the potential for commonality. A common part number for the entire outer wing was the goal. Fuel volume of the outer wing is adequate for all members of the family. Navier-Stokes 


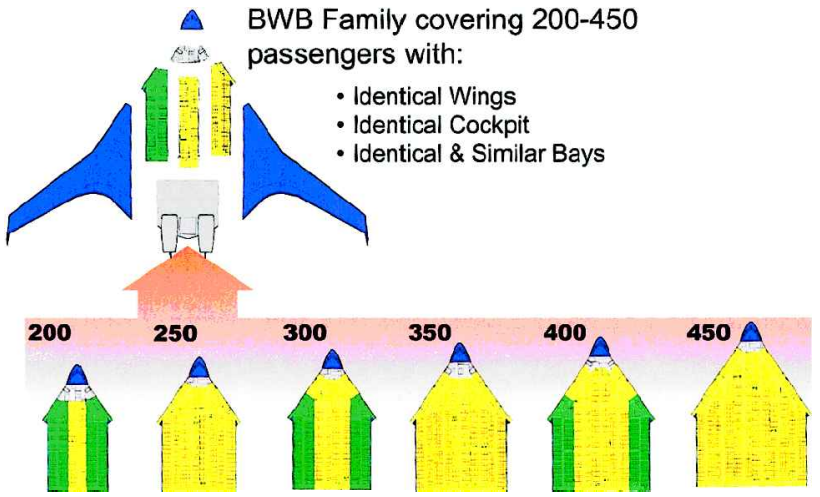

Fig. 34 Commonality of a BWB family.

- Each bay in the BWB is an identical "cross-section"

- The BWB-450 retains $97 \%$ of the BWB-250's furnishings weight

- Identical bagracks, seats, crew rest, lavs, galleys, sidewalls, ceilings, floors

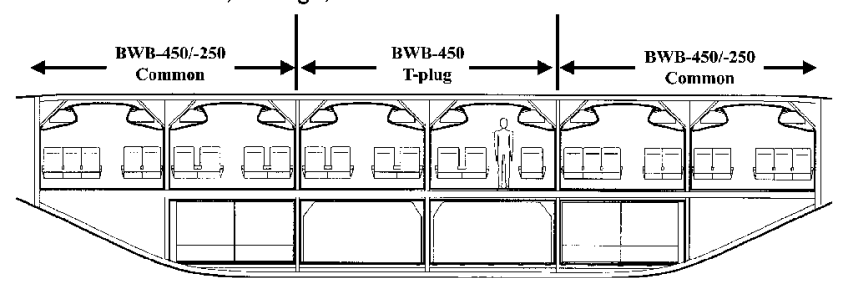

Fig. 35 Cabin cross-sectional growth from 250 to 450 passengers.

analyses of several of the members of this example family demonstrated proper aerodynamic performance. The airplanes are trimmed and balanced. Finite element modeling was used to quantify the effect of commonality on the structure. The proposed commonality was feasible, but at a cost of increased OEW for the smaller airplanes. If the common part number requirement is relaxed to permit a skin gauge change, the OEW penalty is substantially reduced.

Commonality extends naturally to the interior, once the commitment to the centerbody growth concept is made. In principle, the cabin cross section is the same for all of the airplanes, as shown in Fig. 35. This implies common galleys, lavatories, bag racks, and seats. Substantial maintenance and life-cycle cost savings are implied for the airline customer.

Put simply, commonality is a constraint, and almost any constraint imposed on an airplane is manifested by an increase in weight. However, the BWB concept appears to offer the opportunity for an unusual level of commonality while the aerodynamic efficiency is maintained via the natural variation of wing area and span with weight. This implies significant reductionsin part count and learning curve penalties in manufacturing. Enhanced responsiveness to fleetmix requirements is also implied. It remains to evaluate thoroughly the trade between airplane cost and performance offered by the BWB family concept.

\section{Speed}

Figure 36 shows a comparison of the BWB-450 cross-sectional area variation $S(x)$ with that of the classical minimum wave drag due to the volume of the Sears-Haak body. Also shown is the variation for an MD-11. It can be observed that the BWB is naturally arearuled, and, hence, a higher cruise Mach number should be achievable without a change in the basic configuration geometry. Figure 37 gives the results of a WingMOD-based study for the effect of the design cruise Mach number on BWB performance and weight. All of the designs are closed, trimmed, and balanced for the same design mission. Variation between planforms appears slight; however, a comparison between the $M=0.85$ and 0.95 designs shows a sig-

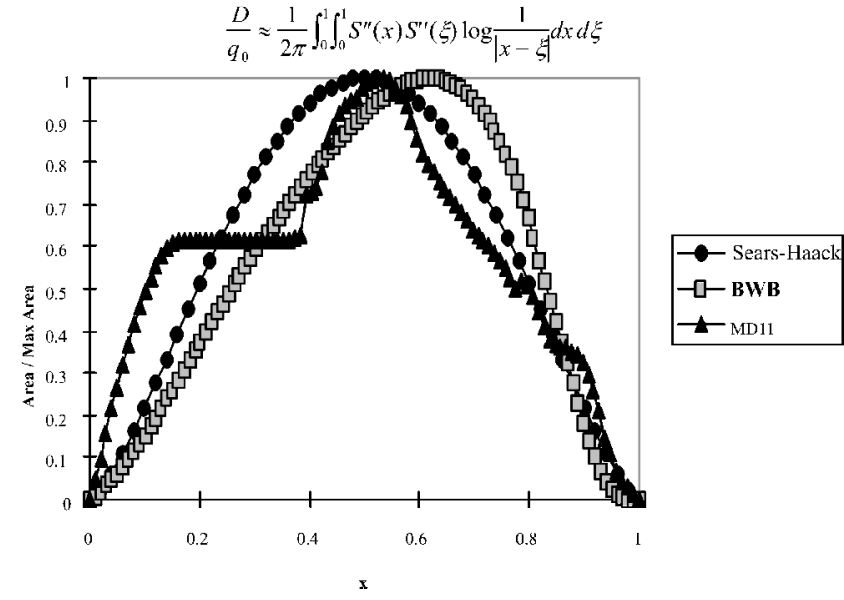

Fig. 36 Cross-sectional area variations, $S_{(x)}$ vs $x$.

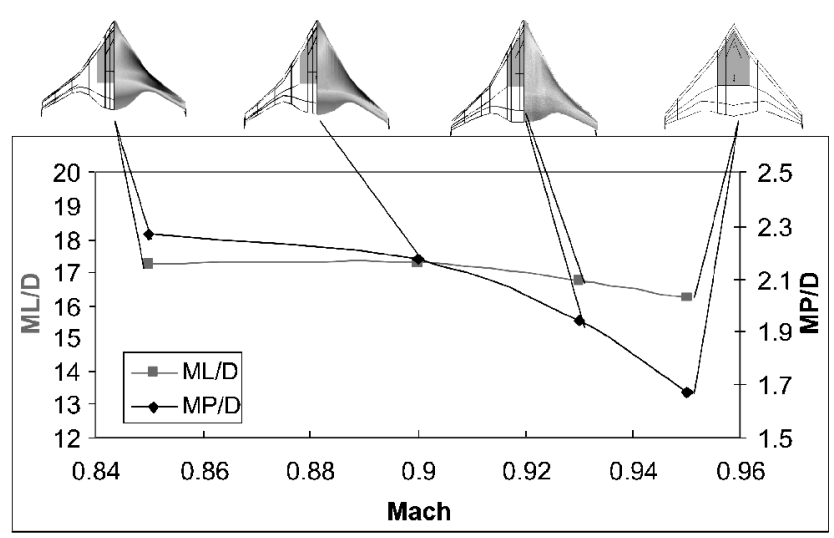

Fig. 37 BWB planform, $M L / D$ and $M P / D$ variation with Mach number.

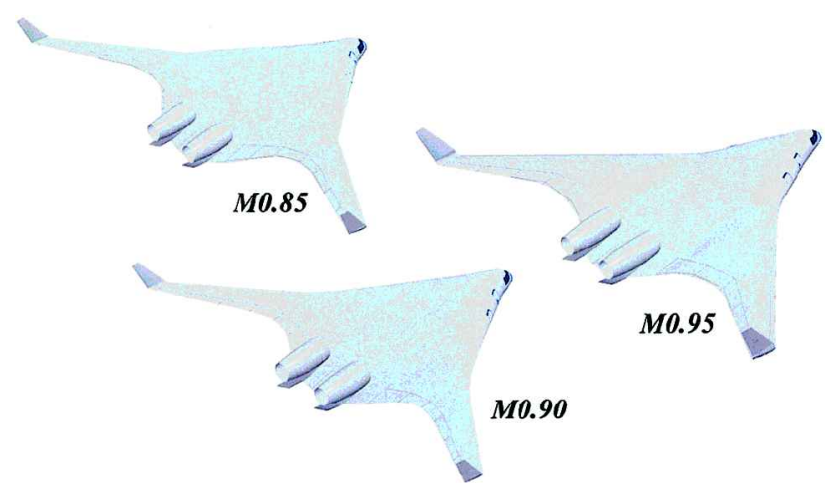

Fig. 38 Comparison of BWB-250 configuration with Mach number.

nificant distinction. Increased Mach number is accommodated by an increase in sweep and chord, which results in a correspondingincrease in weight. Some of this weight increase is due to the increase of installed engine SFC with Mach number. The classic aerodynamic parameter $M L / D$ is plotted as a function of the cruise Mach number in Fig. 37. A more meaningful graph is given by the variation of the parameter $M P / D$, also shown in Fig. 37. ( $P$ is the design payload weight.) $M P / D$ includes the effect of airplane weight itself, because $M P / D=(M L / D) \times(P / W)$. Isometric views of BWBs designed for $M=0.85,0.90$ and 0.95 are given in Fig. 38 .

These preliminary results suggest that 0.90 could be the best cruise Mach number. However, the economic value of speed must be established before selecting a design cruise Mach number. For example, airplane utilizationvaries directly with speed, and for some 
longer-range missions, a slight increase in speed could eliminate the requirement for a second crew. The question then becomes, how much of an increase in TOGW and fuel burn can be offset by such issues? Resolution remains to be found.

\section{Passenger Acceptance, Ride Quality, and Emergency Egress}

The unique interior configuration of the BWB offers both opportunities and challenges. Vertical walls of the passenger cabins provide a more spacious environment, similar to a railroad car rather than the curved walls of a conventional airplane. At the same time, the low capacity of each cabin (approximately 100 passengers) provides an intimacy not available in wide-body conventional transports. However, although there is a window in each main cabin door, there are no windows in the cabin walls. As a surrogate for windows, a flat screen display connected to an array of digital video cameras will make every seat a window seat. Some example interior renderings are shown in Fig. 39.

Ride quality has been a concern due to the lateral offset of the passengers from the center of gravity. This has been addressed by comparison of the results from piloted flight simulator tests of the BWB-450 and a B747-400 using the same pilots and flight profile. One of the more severe cases studied was a takeoff, go-around, and landing in moderate turbulence with a 35-kn crosswind. Lateral and vertical rms $g$ levels were comparable for the "worst" seats in both airplanes; however, the frequency content tended to be lower for the BWB. Gust load alleviation was not used on either airplane.

Emergency egress becomes a significant challenge when passenger capacity exceeds 400 . This is simply a consequence of the square-cube law: Capacity increases with the cube of the length scale, whereas surface area for egress increases with the square of the length scale. The BWB configuration lends itself particularly well to resolving this problem. There is a main cabin door directly in the front of each aisle, and an emergency exit through the aft pressure bulkhead at the back of each aisle. In addition, there are four cross aisles, as shown in Fig. 40.
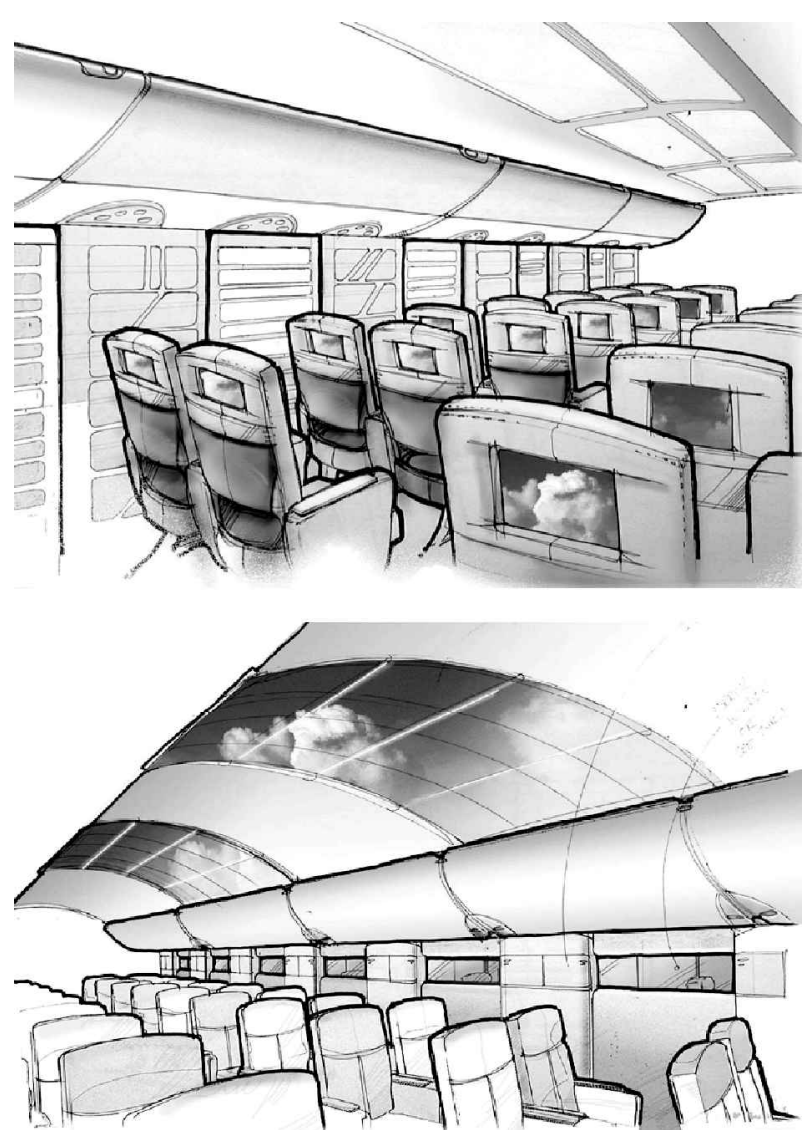

Fig. 39 Interior concepts for the BWB.
Table 3 Issues and areas of risk (from Douglas Aircraft Co., 1955)

- Complex flight control architecture and allocation, with sever hydraulic requirements

- Large auxiliary power requirements

- New class of engine installation

- Flight behavior beyond stall

- High floor angle on take off and approach to landing

- Acceptance by the flying public

- Performance at long range

- Experience and data base for new class of configuration limited to military aircraft
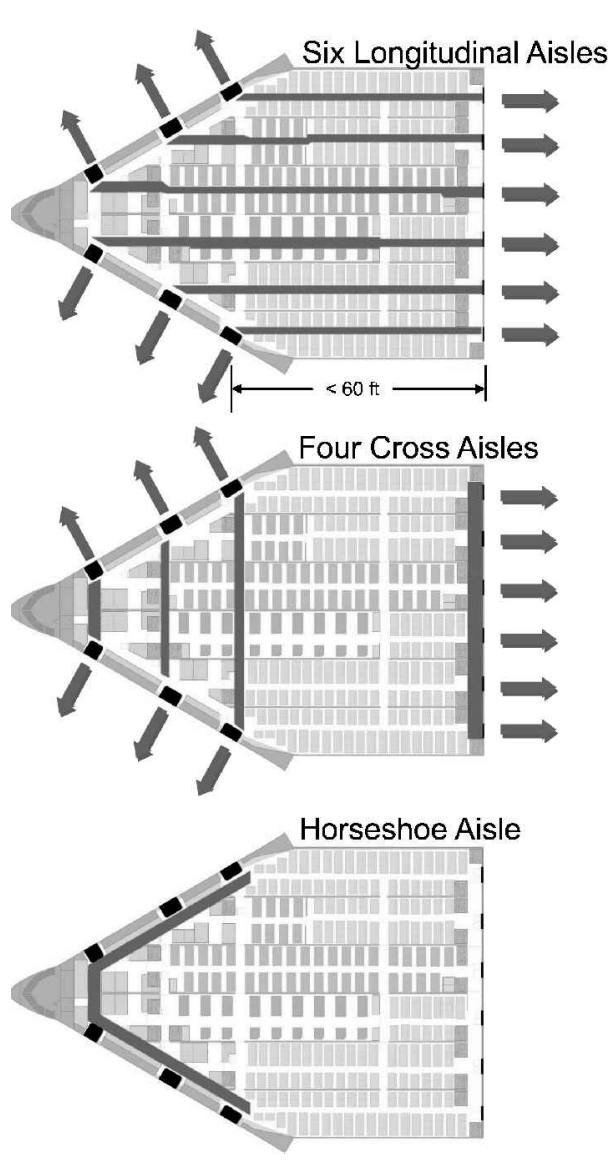

Fig. 40 Cabin egress flow patterns.

Thus, from virtually any location in the cabin, a passenger will have a direct view of one or more exits. Unlike a conventionaltransport, a 90-deg turn will not be required to reach a door from the aisle. Because there is no upper deck, the problems with long slides, slide interference, and overwing exits do not exist. Ultimately, this new class of interior configuration will require a new set of emergency evacuation criteria coordinated with the Federal Aviation Administration

\section{Summary}

Development of the BWB has progressed steadily over the past seven years. Once-apparent "show-stoppers" have been reduced to technical challenges, or, in most cases, proper solutions. From a distance, the Boeing BWB-450 baseline airplane shows little distinction from the first-generation BWB developed under NASA sponsorship in 1993. The intent of this paper has been to chronicle the engineering work that has brought the airplane to the state it is in today. Table 3 presents a list of issues and areas of risk. They could readily apply to the BWB. However, they are, in fact, extracted from Douglas Aircraft Company memoranda written in the 1950 s regarding the challenge of moving from the DC-7 to the DC-8. Hopefully, our industry will press on, just as Douglas and Boeing did 50 years ago. 


\section{Acknowledgments}

The creation and initial development of the Blended-Wing-Body (BWB) concept was stimulated and funded by NASA Langley Research Center, primarily under contract NAS1-20275. NASA involvement with the BWB has continued with their design and fabrication of the BWB Low-Speed Vehicle flight demonstrator.NASA's initiative and involvement with the BWB has been critical to the success of the concept. Their participation is gratefully acknowledged. The BWB exists today because of the contributions of an array of very special engineers. Following is a partial list (partial, because it seems inevitable that a key individual will have been overlooked) of those whose contributions have been fundamental to the development of the BWB: John Allen, Amer Anabtawi, Robert Bird, Ron Blackwelder, Derrell Brown, George Busby, Jerry Callaghan, Peter Camacho, Douglas Cameron, Louis Feiner, Douglas Friedman, Ronald Fox, Richard Gilmore, Raquel Girvin, Antonio Gonzales, Arthur Hawley, Ronald Kawai, Ilan Kroo, David Kwok, Peter Lissaman, Roger Lyon, Jacob Markish, Robert McKinley, Mark Meyer, Joshua Nelson, Alan Okazaki, Wayne Oliver, Mark Page, Dhar Patel, Wilfred Pearce, Regina Pelkman, Chris Porter, Mark Potsdam, Norman Princen, Blaine Rawdon, Melvin Rice, William Rickard, David Rodriguez, Dino Roman, Kevin Roughen, George Rowland, Peter Rumsey, Debbie Runyan, Matt Salcius, Paul Scott,
Robert Seplak, Leonel Serrano, William Small, Norbert Smith, Darrel Tenney, Ben Tigner, William Vargo, Sean Wakayama, William Watson, Jennifer Whitlock, Matthew Wilks, Karen Willcox, Kenneth Williams.

\section{References}

${ }^{1}$ Liebeck, R. H., "Design of Subsonic Airfoils for High Lift," Journal of Aircraft, Vol. 15, Sept. 1978, pp. 549-561.

${ }^{2}$ Liebeck, R. H., Page, M. A., Rawdon, B. K., Scott, P. W., and Wright, R. A., "Concepts for Advanced Subsonic Transports," NASA CR 4624, Sept. 1994.

${ }^{3}$ Liebeck, R. H., Page, M. A., and Rawdon, B. K., "Blended-Wing-Body Subsonic Commercial Transport,” AIAA Paper 98-0438, Jan. 1998.

${ }^{4}$ Anabtawi, A., "Experimental Investigation of Boundary Layer Ingestion into Diffusing Inlets," Ph.D. Dissertation, Aerospace Engineering Dept., Univ. of Southern California, Aug. 1999.

${ }^{5}$ Rodriguez, D. L., "A Multidisciplinary Optimization Method for Designing Boundary Layer Ingesting Inlets," Ph.D. Dissertation, Dept. of Aeronautics and Astronautics, Stanford Univ., Stanford, CA, Jan. 2001

${ }^{6}$ Wakayama, S., "Blended-Wing-Body Optimization Problem Setup," AIAA Paper 2000-4740, Sept. 2000.

${ }^{7}$ Roman, D., Allen, J. B., and Liebeck, R. H., "Aerodynamic Design of the Blended-Wing-Body Subsonic Transport," AIAA Paper 2000-4335, Aug. 2000 .

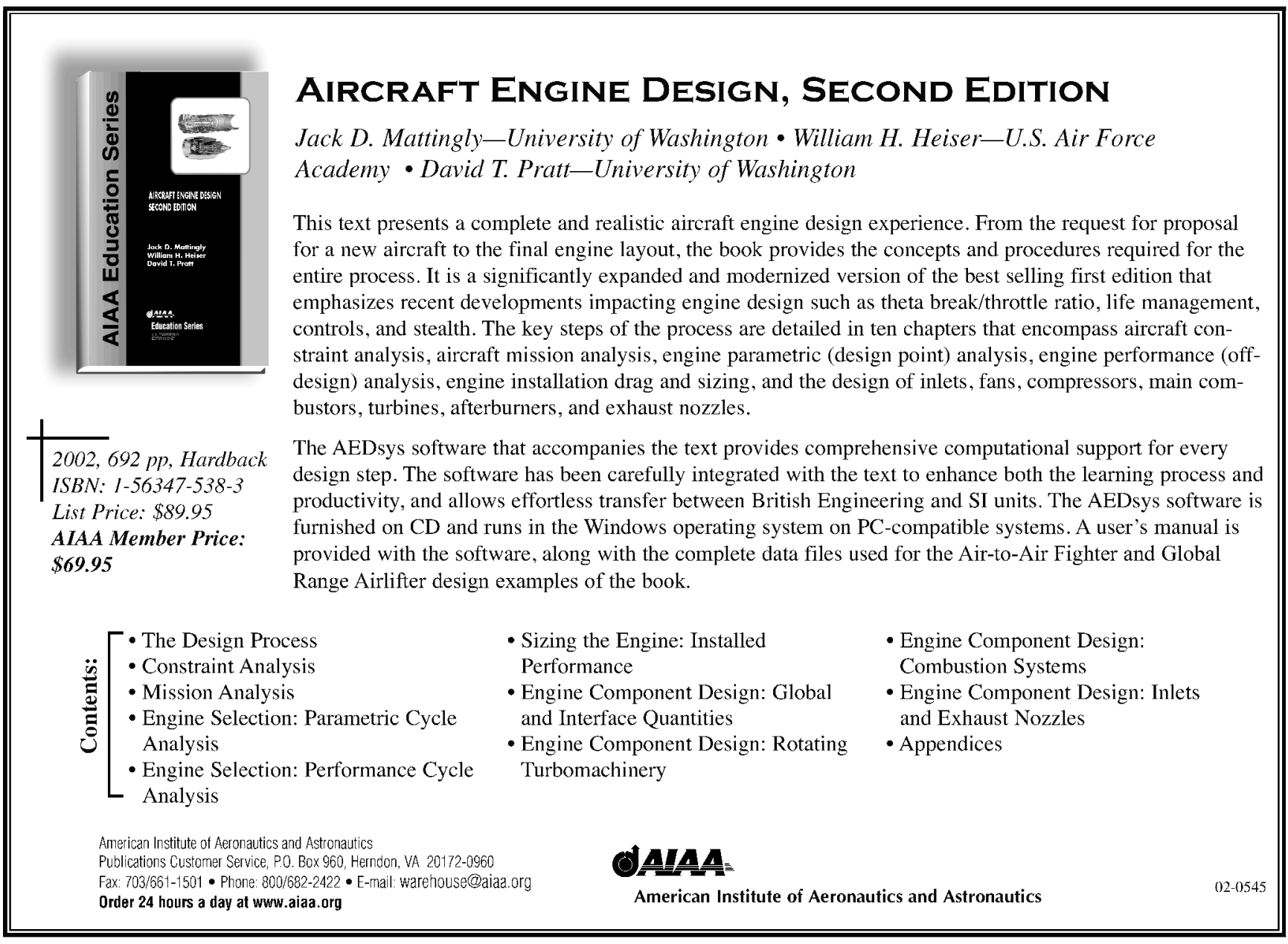

